\title{
A sensor-agnostic albedo retrieval method for realistic sea ice surfaces - Model and validation
}

\author{
Yingzhen Zhou ${ }^{1}$, Wei $\mathrm{Li}^{1}$, Nan Chen ${ }^{1}$, Yongzhen Fan ${ }^{2}$, and Knut Stamnes ${ }^{1}$ \\ ${ }^{1}$ Light and Life Laboratory, Department of Physics, Stevens Institute of Technology, Hoboken, NJ 07307, USA \\ ${ }^{2}$ Cooperative Institute for Satellite Earth System Studies (CISESS), Earth System Science Interdisciplinary Center (ESSIC), \\ University of Maryland, College Park, MD 20740, USA,
}

Correspondence: Yingzhen Zhou (yzhou64@ stevens.edu)

\begin{abstract}
The cryosphere's surface (snow, sea ice, and water) regulates global climate through several feedback mechanisms. Broadband albedo is a critical parameter determining the radiative energy balance of the complex atmosphere-cryosphere system, but there is currently no reliable, operational albedo retrieval product capable of assessing the global sea-ice albedo with sufficient spatial-temporal resolution for studies of sea-ice dynamics and for use in global climate models.

A framework was established for remote sensing of sea ice albedo that integrates sea-ice physics with high computational efficiency, and can be applied to any optical sensor that measures appropriate radiance data. A scientific machine learning (SciML) approach was developed and trained on a large synthetic dataset (SD) constructed using a coupled atmospheresurface radiative transfer model (RTM). The resulting RTM/SciML framework combines the RTM with a multi-layer artificial neural network SciML model. In comparison to the NASA MODIS MCD43 albedo product, this framework does not depend on observations from multiple days, and can be applied to single angular observations obtained under clear-sky conditions. Compared to the existing melt pond fraction-based approach for albedo retrieval, the RTM/SciML framework has the advantage of being applicable to a wide variety of cryosphere surfaces, both heterogeneous and homogeneous. Validation of the RTM/SciML albedo product using MODIS and SGLI data against measurements obtained from aircraft campaigns revealed excellent agreement, with mean absolute error of 0.047 for above 2000 clear-sky pixels.
\end{abstract}

\section{Introduction}

Sea-ice in the Arctic regulates global climate through multiple feedback processes (Robock, 1983; Bitz and Roe, 2004), and the ice-albedo feedback is perceived as one of the most important factors contributing to sea ice thinning in the Arctic (Curry et al., 1995; Gildor et al., 2002). Sea-ice cools Earth by reflecting solar energy back to space and by insulating the ocean water underneath from the atmosphere. An initial warming of sea ice can accelerate the melting process dramatically and thus amplify the surface warming, which makes the ice-covered regions more sensitive to small changes in global temperature and carbon emissions (Pithan and Mauritsen, 2014; Comiso and Hall, 2014).

It is not new that Arctic sea ice has been on the decline in the past years (Stroeve et al., 2007; Serreze et al., 2007; Kwok and Rothrock, 2009; Tschudi et al., 2016). In some areas of the Arctic, the average sea ice thickness near the end of the melt season 
has decreased by two-third over the last six decades (Kwok, 2018). Some researchers even made postulations, forecasting the year when the first ice-free summer would occur in the Arctic (Wang and Overland, 2012).

For decades, optical sensors deployed on geostationary and polar-orbiting satellites have been used to derive the global-scale surface broadband albedo. However, geostationary satellites can only offer data within the latitude range of $60^{\circ} \mathrm{S}$ to $60^{\circ} \mathrm{N}$, omitting the polar regions entirely. With regard to polar-orbiting satellites, the majority of albedo products are land-surface products, while ocean surface albedo data (including sea-ice) are left blank (Qu et al., 2015). Table 1 compares the currently operational products and algorithms capable of retrieving albedo at the cryosphere's surface.

\begin{tabular}{l|l|l}
\hline Albedo Product (sensor) & Description & reference \\
\hline APP-x (AVHRR) & 25-km spatial resolution & Key et al. (2016) \\
\hline CLARA-SAL (AVHRR) & 25-km spatial resolution; only contains data in southern of 80N & Riihelä et al. (2013) \\
\hline MCD43 (MODIS) & $\begin{array}{l}\text { land albedo product; daily product smoothed with 16-day period; only provides lim- } \\
\text { ited sea-ice data near the coast }\end{array}$ & $\begin{array}{l}\text { Lucht et al. (2000); Schaaf } \\
\text { et al. (2002) }\end{array}$ \\
\hline $\begin{array}{l}\text { MPD-based (MERIS, } \\
\text { OLCI) }\end{array}$ & $\begin{array}{l}\text { 1-km resolution mapped to 12.5-km NSIDC grid; albedo on open-water omitted; the } \\
\text { MPD algorithm has only been applied to two sensors so far; the MERIS product was } \\
\text { validated against MELTEX airborne data }\end{array}$ & $\begin{array}{l}\text { Zega et al. (2015); Istomina } \\
\text { (2020) }\end{array}$ \\
\hline $\begin{array}{l}\text { Qu's direct-estimation } \\
\text { (MODIS) }\end{array}$ & $\begin{array}{l}\text { validated on snow-covered land and around 50 data points of ship-borne measure- } \\
\text { ments, LUT generated with an uncoupled RTM, without melt-pond inclusion }\end{array}$ & Qul. (2016) \\
\hline $\begin{array}{l}\text { Peng's direct-estimation } \\
\text { (VIIRS) }\end{array}$ & $\begin{array}{l}\text { validated against measurement on Greenland Ice Sheet, LUT generated with an un- } \\
\text { coupled RTM Peng et al. (2018) }\end{array}$ & \\
\hline
\end{tabular}

Table 1. Summary of the currently operational products and algorithms capable of retrieving albedo at the cryosphere's surface.

Notably, due to a scarcity of validation data over the sea-ice surface, only the MERIS-albedo product was validated using a sufficient number of data points $(>100)$ against actual sea-ice albedo measurements. However, the MERIS sensor has been inactive since 2012 (Istomina et al., 2015). Although the OLCI-albedo product is the successor of MERIS (Istomina, 2020), which was also generated based on the melt-pond detector (MPD) algorithm (Zege et al., 2015), a comparison of the OLCI-albedo with aircraft observations (see Section 4.3) reveals an overestimation of the OLCI-albedo over the snow-covered sea-ice surface. The two direct-estimation products (hereafter referred as Qu's and Peng's, Qu et al. (2016); Peng et al. (2018)) have been validated using ground truths from the Greenland Ice Sheet and snow-covered land, but the validation is not representative of the highly variable sea-ice surface. While Qu's product was also compared to measurements from the Tara polar ocean expedition, an R-squared value of 0.67 , based on daily-average albedo from cruise measurements with fewer than 50 matched retrieval-measurement data points during the 90-day expedition, indicates that the two data sources (measurements and retrieval) are similar, but does not provide statistical evidence for the albedo product's reliability.

Three terminologies are used to refer to the albedo of a surface (Schaepman-Strub et al., 2006): 
- Directional-hemispherical reflectance (DHR), or alternatively, 'black-sky albedo' (BSA): the surface albedo in the absence of a diffuse radiance component (i.e., atmosphere); incoming radiation is unidirectional, and the albedo is a function of solar zenith angle.

- Bi-hemispherical reflectance (BHR), alternatively referred to as 'white-sky albedo' (WSA): the incident radiation is devoid of a direct component (i.e. completely diffuse and isotropic illumination).

- Blue-sky albedo: the real albedo under given atmospheric and illumination conditions (eq. 2), which can be approximated as the weighted average of DHR and BHR, with weights corresponding to the proportions of the beam and diffuse illumination.

The CLARA-SAL product (Riihelä et al., 2013) calculates the 'black-sky albedo', the App-x and MCD43 products generate both black- and white-sky albedo (Schaaf et al., 2002), and all other albedo products directly yield 'blue-sky albedo', which is also the albedo that can be directly compared to with in situ measurements.

Note that the broadband albedo estimated by APP-x is based on a narrow-to-broadband conversion (NTBC) of reflectance under a Lambertian-surface assumption (Key et al., 2016), which implies that the radiance reflected from the surface is isotropic and the value of albedo equals $\pi$ times the reflected radiance. However, fresh snow and white ice surfaces cannot be considered Lambertian; dry snow and ice surfaces exhibit strong forward-scattering, and the impact of the bidirectional distribution of radiance reflected must be rectified in a post-processing step as discussed by Li et al. (2007).

Apart from the definitional difference and Lambertian reflector invalidity of CLARA-SAL and APP-x, the spatial resolution of the two products (both $25 \mathrm{~km}$ ) is insufficient for characterizing the heterogeneous cryosphere surface. As a result, comparisons to the two legacy products will not be considered in this study.

The spectral bi-directional reflectance distribution function (BRDF) can be used to describe the angular distribution of surface scattering as functions of illumination and viewing geometries at a particular wavelength. It is denoted by $R\left(\theta, \theta_{0}, \varphi, \lambda\right)$, where $\theta$ and $\theta_{0}$ are the zenith angles of the observation and illumination directions, respectively, and $\varphi$ is the azimuth angle between them (Martonchik et al., 2000). Currently, two methods are available for estimating surface broadband albedo that take the cryosphere's BRDF into account: BRDF angular modeling and the direct-estimation algorithm (Qu et al., 2015). The MCD43 product uses BRDF angular modeling, the melt-pond detector (MPD)-based products use radiative transfer model (RTM) simulations to obtain analytical solutions to BRDF (which can be considered a form of angular modeling), and Qu's as well as Peng's VIIRS sea ice albedo (VSIA) products both use the direct-estimation method.

From a methodological standpoint, none of the aforementioned algorithms can establish a direct relation between TOAmeasured radiance and surface albedo; the radiative processes in the atmosphere and on the cryosphere surface were considered independently (i.e. 'uncoupled'). The atmospheric reflectance and transmittance are calculated with RTMs (for the Melt Pond Detection (MPD)-based algorithm, the RAY model is used (Tynes et al., 2001); for the direct-estimation approach, the 6S model is used (Vermote et al., 1997)). Following this step, the calculated values are used to determine the TOA radiance/reflectance that corresponds to the specific surface condition as defined by the surface BRDF values. 
In contrast, we present a framework that integrates a coupled atmosphere-surface radiative transfer model (RTM), AccuRT (Stamnes et al., 2018), with scientific machine learning (SciML) models. The coupled RTM model considers all radiative processes occurring in the coupled atmosphere, snow/ice system, including the atmosphere-surface interface, as well as multiple reflections between the surface and the atmosphere. Atmospheric molecular and aerosol-induced modifications to the incident spectral distribution of the solar radiation are also taken into account. At the atmosphere-surface interface Fresnel's equations and Snells' law appropriately describe light interactions as required if the index of refraction changes across the interface. Additionally, this RTM is combined with a snow/ice/water model that accurately simulates the snow/ice crystals and their inherent optical properties, the snow/ice/melt-pond layering, and the impurities included within the snow/ice/water layers (Stamnes et al., 2011).

To retrieve albedo, a synthetic dataset (SD) was constructed using the coupled-RTM. It consists of TOA radiances observed in suitable satellite channels as a function of observational and solar angles, as well as the associated broadband albedo at the surface. This SD encompasses a range of different surface types, including snow-covered ice, melt ponds, and bare sea ice, as well as their mixtures. All optical properties of surface and atmospheric constituents, as well as radiative processes within the coupled atmosphere-surface system, are deduced from first principles. The accurate RTM ensures that the 'forward problem' is solved correctly, yielding reliable total radiance and irradiance values at any location of the atmosphere-ice-snow-water system given the inherent optical properties of the system constituents.

Following the physically consistent $\mathrm{SD}$, which is designed to be representative of the cryosphere surface in the real world, SciML models can be used to solve the 'inverse problem', which answers the question, 'given the observed TOA radiance and the sun-satellite geometry angles, what is the surface albedo of the sea ice surface?' through an implicit iterative process (i.e. by minimizing a loss function repeatedly during the training of the neural network based SciML methods).

This paper is structured as follows: Section 2 summarizes previous algorithms for sea ice albedo retrieval, introduces the SciML technique, and discusses the cloud screening and surface classification model used in this study. Section 3 is devoted to validation of the albedo-retrieval product, discussion of potential causes of uncertainty, and a sensor-to-sensor comparison of the retrieval outcomes using MODIS and SGLI radiance data. Following validation, the albedo product is compared to the MCD43 product (Section 4.1) and two MPD-based products (MERIS and OLCI, respectively in Sections 4.2 and 4.3.

While prior uses of SciML in remote sensing remained at the "application" stage, we went one step further and extracted global and local interpretations from trained SciML models to determine whether they had learned the physics inherent in the physical model (i.e. physical-consistency of the SciML models with the radiative transfer simulations). The physical consistency of the albedo retrieval model is described in Zhou et al. (2021 (ready to submit), as well as its applicability to cloud radiative forcing $(\mathrm{CRF})$ analysis and to enhancement of current regional/global climate models.

\section{Methodology}

The spectral albedo at a particular wavelength $(\lambda)$ is

$\alpha(\lambda)=\frac{F^{+}(\lambda)}{F^{-}(\lambda)}$ 
where $F^{+}(\lambda)$ and $F^{-}(\lambda)$ are the upward and downward spectral irradiances.

The broadband (wavelength-integrated) albedo $\left(\alpha_{i-j}\right)$ is the ratio of the integrated upward irradiance $\left(F^{+}\right)$to the downward irradiance $\left(F^{-}\right)$, which can be expressed as

$\alpha_{i-j} \equiv \frac{F^{+}}{F^{-}}=\frac{\int_{\lambda_{i}}^{\lambda_{j}} F^{+}(\lambda) d \lambda}{\int_{\lambda_{i}}^{\lambda_{j}} F^{-}(\lambda) d \lambda}$.

The limits of integration span the incident solar spectrum (300-2800 nm), 300-700 nm for the visible band (VIS), 700-2800 $\mathrm{nm}$ for the near-infrared band (NIR), and 300-2800 $\mathrm{nm}$ for the shortwave band (SW).

\subsection{Existing albedo retrieval procedures and their constraints}

In general, the (broadband) albedo retrieval models developed to date require three steps: (1) atmospheric correction (De Keukelaere et al., 2018; Kokhanovsky et al., 2020); (2) anisotropy correction to obtain narrow-band or spectral albedo (Lucht et al., 2000; Ren et al., 2021); and (3) use of NTBC to integrate over the appropriate spectral range to obtain, or alternatively, derive coefficients to estimate, broadband albedo (Knap et al., 1999; Liang, 2000; Xiong et al., 2002; Stroeve et al., 2005).

The MCD43 product describes the effect of reflectance anisotropy on land/ocean surfaces using the RossThick-LiSparse (RTLSR) model provided by Lucht et al. (2000), which is a semi-empirical linear kernel-driven model that requires a sufficient amount of cloud-free observations within a 16-day window. As a result, data gaps of between $20 \%$ and $40 \%$ have been detected (Liu et al., 2013). Additionally, because MCD43 is a land-albedo product, it only delivers very limited shortwave albedo values near the coast due to the lack of a BRDF value for sea ice surface (discussed in detail in Section 4.1). In fact, there are only a few BRDF measurements that can be used to assist in correcting the anisotropy of snow and sea ice surfaces (e.g. Gatebe et al. (2005); Dumont et al. (2010); Gatebe and King (2016)), and they are far from conclusive in covering the complicated sea ice surface or encompassing a sufficient angular and spectral range.

Due to the scarcity of observations, in the two proposed methods, the BRDF values of the cryosphere surface are approximated using radiative transfer models. The MPD-based and direct-estimation methods compute the BRDF by characterizing each pixel as a 'linear blended' surface of sea-ice/snow/melt-pond/water. In the MPD-based method, the surface BRDF is linearly weighted with the sea ice and melt pond BRDFs; open water is excluded, and snow-covered ice conditions are approximated by modifying the threshold reflectance values (more specifically, the spectral reflection coefficients, Zege et al. (2015)). In Qu's algorithm, the BRDF is the weighted average of sea ice, snow-covered ice, and open water, with melt-pond conditions omitted (Qu et al., 2016). Based on Qu's algorithm, the VSIA product (Peng's algorithm, Peng et al. (2018)) evaluates all four surface conditions and derives the melt-pond's BRDF based on the MPD algorithm.

While the two BRDF approaches (Zege et al., 2015; Qu et al., 2016), in comparison to the MCD43 product, do not rely on $a$ priori observations to construct the BRDF values and can be applied to any angular observation from the satellite sensor during any transit, they do share a common limitation in that they typically rely on certain empirically-derived criteria (or threshold values) to determine the exact type and composition of the corresponding pixel in order to assign an appropriate BRDF or filling value (for invalid observations). In other words, the surface type was empirically designated prior to albedo estimation. Misclassification or improper manual assignment would result in a considerable uncertainty in the final albedo estimate. 
The narrow-band to broadband albedo conversion stage introduces an additional source of uncertainty, as it requires fitting yet another function. Due to the scarcity of observational data and persistent cloud cover, obtaining the spectral albedo over all possible combinations of sea ice surfaces is challenging. Even when fitted with spectral albedo values calculated from insitu irradiance measurements, an RMSE of 0.02 to 0.032 is introduced during the fitting procedure; these values correspond to the NTBC in Pohl et al. (2020) and Zege et al. (2015), where coefficients were fitted using ground-based land-fast ice measurements and airborne pyranometer measurements, respectively. On the other hand, in the BRDF-based direct estimation method, the NTBC coefficients are acquired directly from the BRDF database (Liang, 2005; Wang et al., 2013). Additionally, due to the differences in the central wavelengths and saturation conditions of various sensors, the NTBC coefficients need to be adjusted on a sensor-by-sensor basis (Liang, 2000; Stroeve et al., 2005).

To conclude, all available retrieval methods require fitting of at least two functions to obtain the broadband albedo: one for integrating the spectral bands and another for dealing with the angular dependence of the reflected radiance. The primary issues with these methods are twofold: (1) the decoupling of radiative transfer processes in the atmosphere-surface system and (2) the discordance of adopted snow/sea ice optical characteristics with those found in nature. A coupled RTM that is used in conjunction with a realistic modeling of the system based on its IOPs can address both of these challenges.

\subsection{A new method for albedo-retrieval: Scientific machine learning based on a coupled RTM}

The AccuRT Radiative Transfer model (Stamnes et al., 2018) is able to simulate a coupled system with changes of refractive index across the atmosphere-ocean interface. Inputs to the coupled RTM are the inherent optical properties (IOPs) of the two adjacent coupled slabs (upper slab is atmosphere/snow and lower slab is ocean/ice). Each slab can be partitioned into many adjacent layers, with the IOPs being constant within each layer but varying between them. The IOPs depend on the medium's absorption and scattering coefficients, as well as the scattering phase functions. Within the AccuRT computer code, Mie theory and the particle size distributions are used to generate IOPs based on user-defined physical properties of the medium (Stamnes et al., 2011). Table 2 summarizes the parameters used to calculate the IOPs of bare ice, snow-covered ice, open water, meltponds, and aerosols.

Among the sea ice inclusions, air bubbles are modeled as pure scatterers, brine pockets scatter and absorb light, and black carbon impurities mainly absorb light. The effective grain size $r_{e}$ of snow particles closely resembles the effective light path traveled by a photon, and hence a larger $r_{e}$ suggests a lower reflectance (and albedo). Additionally, bulk properties such as ice/pond/snow thickness $\left(h, h_{\mathrm{m}}, h_{\mathrm{s}},\right)$ and density $\left(\rho_{s}\right)$ also impact the optical depth of the medium. Notably, the parameterizations employed here are consistent with the physics of sea ice/snow/water (Grenfell and Maykut, 1977; Grenfell and Perovich, 1984; Warren, 2019).

To summarize, AccuRT's nature as a coupled RTM and as a model that incorporates the physical properties of ice/snow/water to calculate their IOPs provides the following benefits in order to tackle the 'forward problem':

1. There is no need to (i) perform atmospheric correction, (ii) build a BRDF dataset, or (iii) employ angular modeling or anisotropy correction. All these effects are implicitly included in the coupled RTM. 


\begin{tabular}{|c|c|c|c|}
\hline Type & Parameter & Properties & Comments \\
\hline \multirow{7}{*}{ bare ice } & \multirow{7}{*}{$X_{i c e}$} & $h$ & sea ice thickness \\
\hline & & $V_{\mathrm{br}}$ & brine pocket volume fraction \\
\hline & & $r_{\mathrm{br}}$ & brine pocket radius \\
\hline & & $V_{\mathrm{bu}}$ & air bubble volume fraction \\
\hline & & $r_{\mathrm{br}}$ & air bubble radius \\
\hline & & $f_{\mathrm{bc}, \mathrm{i}}$ & black carbon impurity fractions in ice \\
\hline & & $X_{\text {water }}$ & physical properties of the ocean water beneath the sea ice layer \\
\hline \multirow{6}{*}{ snow-covered ice } & \multirow{6}{*}{$X_{\text {snow }}$} & $r_{\mathrm{e}}$ & effective grain size of snow particles \\
\hline & & $\rho_{\mathrm{s}}$ & snow density \\
\hline & & $h_{\mathrm{s}}$ & snow depth \\
\hline & & $f_{\mathrm{bc}, \mathrm{s}}$ & black carbon impurity fractions in snow \\
\hline & & $X_{\text {ice }}$ & physical properties of the sea ice below the snow-cover layer \\
\hline & & $X_{\text {water }}$ & physical properties of the ocean water beneath the sea ice layer \\
\hline \multirow{3}{*}{ ocean water } & \multirow{3}{*}{$X_{w a t e r}$} & $h_{\mathrm{w}}$ & open-water depth \\
\hline & & $f_{\text {chl }}$ & chlorophyll-a concentration \\
\hline & & $f_{\mathrm{CDOM}}$ & colored dissolved organic matter (CDOM) concentration \\
\hline \multirow{3}{*}{ melt-pond } & \multirow{3}{*}{$X_{m e l t}$} & $h_{m}$ & melt pond thickness \\
\hline & & $X_{\text {ice }}$ & physical properties of the sea ice below the melt pond layer \\
\hline & & $X_{\text {water }}$ & physical properties of the ocean water below sea ice layer \\
\hline aerosol & $X_{\text {aerosol }}$ & $\tau_{\text {aero }}$ & aerosol optical depth in the atmospheric layer \\
\hline
\end{tabular}

Table 2. Properties to acquire the inherent optical properties (IOPs) of bare ice, snow-covered ice, open water, melt-pond, and aerosol, which are utilized as inputs to the radiative transfer model (Stamnes et al., 2011). 
2. Because each simulation performed by the coupled RTM represents a combination of (atmosphere/surface conditions, sun-sensor zenith and azimuth angles), a SD can be constructed that is designed to include (i) the complicated surface and atmosphere conditions by varying the optical properties in Table 2, and (ii) the possible combinations of illumination/viewing geometries.

With a comprehensive SD, we are not restricted to a linear regression model (as in the direct-estimation method) to derive the relationship between the spectral radiance at TOA and the blue-sky albedo at the surface; any reliable SciML model may be evaluated and compared as long as it is capable of solving the 'inverse problem' (i.e. a regression model, with albedo being the target and the radiances as well as sun-satellite geometry angles being the features).

In the SD we constructed, the temperature, pressure, and concentrations of the major atmospheric elements were described using the 'subarctic summer' atmospheric profile (Anderson et al., 1986). The aerosol optical depth (AOD) values were taken with ranges reasonable in cryosphere areas (Mehta et al., 2016; Winker et al., 2013).

Pseudo-random values of the physical parameters of ice, water, and snow within realistic ranges were applied to generate 158,000 cases each for (i) bare-ice, (ii) ice with melt water, and (iii) ice with snow cover. These surface and atmospheric parameters, together with randomly distributed solar/viewing geometries form a dataset suitable for generating a SD of TOA radiances and corresponding albedo values that can be used to train a MLANN algorithm (see Zhou et al. (2021 (submitted) for detail).

Altogether, the 474,000 configurations cover most expected combinations of surface types and atmospheric conditions during the sea ice life cycle. For each case, TOA radiances at appropriate sensor channels (channel specifications in Section 2.3) as well as the three broadband albedo values $\left(\alpha_{\mathrm{VIS}}, \alpha_{\mathrm{NIR}}, \alpha_{\mathrm{SW}}\right)$ were computed based on downward and upward irradiances simulated using the coupled-RTM (Stamnes et al., 2018).

After appropriately training a SciML model and evaluating the retrieval results against the validation data (in-situ measured albedo), the model is ready for deployment to retrieve albedos using data obtained from satellite sensors. More specifically, using Level 1B radiance data and the corresponding illumination-observation angles, this albedo product is stored in an $\mathrm{H} 5$ file containing the three broadband albedos, one for each pixel in the input. In other words, the albedo product is compatible with any optical sensor capable of measuring TOA radiance in suitable wavelength channels, and the albedo map's spatial resolution matches that of the sensor footprint.

Additionally, rather than relying on empirical relationships between radiances to establish threshold values for surface classification, a separate SciML model was trained using the RTM to address the 'inverse problem' of surface classification and cloud screening. The independent surface classification model ensures that even on highly heterogeneous surfaces or in conditions where classification on certain pixels is difficult (e.g. the long-standing difficulty in distinguishing between slushy mixtures of ice and water, very thin ice, and melt ponds), the retrieval of their surface albedo values is unaffected.

In this study, the TOA radiances from the Moderate Resolution Imaging Spectroradiometer (MODIS) and the Secondgeneration GLobal Imager (SGLI) were employed for albedo retrieval. While only two sensors are discussed, the retrieval method is generic and applicable to any satellite sensor having suitable radiance data (e.g. the Visible Infrared Imaging Radiometer Suite, abbreviated as VIIRS). 


\subsection{Radiance data from the MODIS and SGLI sensors}

MODIS Level 1B calibrated radiance data (MOD021) and Level 1A geolocation fields (MOD03) are used to retrieve the albedo and obtain the cloud screening and surface classification. We employ the radiances of seven channels: blue (459-479 $\mathrm{nm}$ ), green $(545-565 \mathrm{~nm})$, red $(620-670 \mathrm{~nm})$, near infrared $(841-876 \mathrm{~nm})$, and the three shortwave infrared bands 1230-1250 nm, 1628$1652 \mathrm{~nm}$, and 2105-2155 nm. All channels have been aggregated at a common resolution of $1 \mathrm{~km}$. The data are acquired from the Atmosphere Archive \& Distribution System (LAADS) of the Distributed Active Archive Center (DAAC).

Onboard the Global Change Observation Mission-Climate (GCOM-C) satellite, the Second-generation Global Imager (SGLI) has 11 channels with a spatial resolution of 250 meters. The retrievals were performed using TOA radiances from three channels provided by the infrared scanner (SGLI-IRS) and three channels provided by the visible and near-infrared radiometer (SGLI-VNR) on the SGLI sensor. These six channels are: VN3 (443 nm), VN5 (530 nm) and VN11 (868.5 nm), SW1 (1050 $\mathrm{nm})$, SW3 $(1630 \mathrm{~nm})$, and SW4 $(2210 \mathrm{~nm})$. Due of the 1-km spatial resolution of the VN9, SW1, and SW4 channels, all 250-m data were mapped to fit the $1-\mathrm{km}$ grid.

It is important to note that the observation by MODIS on Terra and by SGLI on GCOM-C are only 15 minutes apart. The retrieval results from the MODIS and SGLI sensors are compared in Section 3.

\subsection{Neural network model}

Neural network models, specifically models with the multi-layer artificial neural network (MLANN, also known as a Multilayer Perceptron, MLP) structure, have been demonstrated to be useful for retrieving and estimating snow and sea ice parameters. Successful implementations include the sea ice and snow thickness retrievals using microwave data (Herbert et al., 2021; Hu et al., 2021; Zhu et al., 2021; Wang et al., 2020; Braakmann-Folgmann and Donlon, 2019; Lee et al., 2019; Tedesco and Jeyaratnam, 2016; Cao et al., 2008; Tedesco et al., 2004), and sea ice concentration (SIC) or melt pond fraction (MPF) retrievals using radiance or reflectance data (Chi et al., 2019; Karvonen, 2017; Rösel and Kaleschke, 2012).

A MLANN's computational unit is a neuron (alternatively called a perceptron), which is organized in a network topology. A set of functions $f_{j}\left(x ; w_{j}, b_{j}\right)$ connected in a chain can be used to describe the architecture of a fully connected neural network with $n$ layers in total (including the input and output layers):

$F(y)=f_{n}\left(\ldots f_{3}\left(f_{2}\left(f_{1}(x) \times w_{1}+b_{1}\right) \times w_{2}+b_{2}\right) \ldots\right)$.

The previous layer's output is transformed by $f_{j}(x) \times w_{j}+b_{j}$, and then an activation function $f_{j+1}$ (which is typically nonlinear) is applied to perform an element-wise operation.

Generally, as the network grows deeper, the features become more abstract and complicated, as each succeeding layer is constructed from the already transformed features of the prior layer (LeCun et al., 2015). The network's $n-2$ hidden layers enable it to describe non-linear relations between the independent and dependent variables $(x, y)$. The matrices $w_{j}$ define the weights for linear transformations between layers, whereas the vectors $b_{j}$ define the biases. The final layer (output layer) has three neurons encoding the predicted albedo values ( $\left.\hat{\alpha}_{\mathrm{VIS}}, \hat{\alpha}_{\mathrm{NIR}}, \hat{\alpha}_{\mathrm{SW}}\right)$. 
To obtain an efficient MLANN, both the network structure's topology and hyperparameters should be tweaked properly. The network architecture selection (NAS) in this study was determined using Auto-Keras and numerical experimentation. Auto-Keras (Jin et al., 2019) is an open-source library for performing automatic machine learning (AutoML) on deep learning models.

Two MLANN models were trained. In Section 3, results from one MLANN was used to retrieve albedo values for comparison with the albedometer measurements $\left(\alpha_{\mathrm{VIS}}, \alpha_{\mathrm{NIR}}, \alpha_{\mathrm{SW}}\right)$ and results from another MLANN was used to retrieve albedo values for comparison against pyranometer measurements $\left(\alpha_{\mathrm{SW}}\right)$.

\subsection{Surface classification and cloud filtering}

Imperfect cloud screening brings considerable uncertainty to the retrieved sea ice albedo. To mitigate this uncertainty, pixels covered by clouds are detected and removed by a machine learning (neural network) based cloud screening and surface classification algorithm (MLCM) developed by Chen et al. (2018). The MLCM (short for Machine Learning Classification Mask) is a threshold-free algorithm trained by extensive radiative transfer simulations. It can be applied to a great variety of surface types to provide reliable cloud mask and surface classification. The MLCM also has the capability to distinguish snow covered sea ice pixels (with a minimum snow depth of $1 \mathrm{~cm}$ ) from bare sea ice pixels. A comparison between the MLCM and other standard cloud mask algorithms showed that the MLCM is better able to detect cloud edges and deal with high solar zenith angles (Chen et al., 2018). Section 3 indicates that the MLCM can assist in filtering cloud, fog (sea smoke) and hazy atmospheric conditions.

\section{Validation}

Three campaigns conducted in the Arctic provided broadband irradiance data across the Arctic sea ice surface. They are: the ACLOUD (Arctic Cloud Observations Using Airborne Measurements During Polar Day) campaign conducted during the 2017 spring-summer transition, the AFLUX (airborne measurements of radiative and turbulent FLUXes of energy and momentum in the Arctic boundary layer) campaign, which took place in April 2019 north of Svalbard, and the MOSAiC (Multidisciplinary drifting Observatory for the Study of Arctic Climate) campaign, which was conducted in late August to September 2020 (Wendisch and Brenguier, 2013; Lüpkes, 2017; 201, 2016).

The broadband albedo was estimated using upward and downward irradiance data collected by two pairs of CMP-22 pyranometers $(0.2 \sim 3.6 \mu \mathrm{m})$ (Stapf et al., 2019, 2021a). The pyranometers operate at a frequency of $20 \mathrm{~Hz}$ and were mounted on the Polar 5 (the ACLOUD campaign used an additional aircraft, Polar 6) research aircraft. Pre-processing was used to avoid data received during high aircraft pitch/roll angles and suspicious equipment frost conditions. Technical details of the pyranometer are provided by Wendisch and Brenguier (2013).

Although the SciML models were trained using irradiance in the wavelength range of 0.3 to $2.8 \mu \mathrm{m}$ rather than the pyranometer's 0.2 to $3.6 \mu \mathrm{m}$ range, we would expect a small error due to the wavelength range difference, because there is virtually 
https://doi.org/10.5194/tc-2021-397

Preprint. Discussion started: 18 January 2022

(c) Author(s) 2022. CC BY 4.0 License.

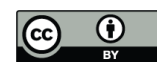

no radiation reaching the surface of the Earth for wavelengths shorter than $0.3 \mu \mathrm{m}$ due to ozone absorption in the stratosphere, and because the contribution to the albedo for wavelengths beyond $2.5 \mu \mathrm{m}$ is negligible.

Along with the pyranometers on Polar 5 and 6, a Spectral Modular Airborne Radiation measurement system ("SMART Albedometer") on Polar 5 measured spectral irradiances between 0.4 and $2.155 \mu \mathrm{m}$ at a frequency of $2 \mathrm{~Hz}$ during the ACLOUD and MOSAiC campaigns (Jäkel et al., 2018, 2021b). To make use of the spectral range provided by the "SMART Albedometer", we adjusted the broadband integration ranges for visible ( $\left.\alpha_{\mathrm{VIS}}, 0.4 \sim 0.7 \mu \mathrm{m}\right)$, near infrared $\left(\alpha_{\mathrm{NIR}}, 0.7 \sim 2.1 \mu \mathrm{m}\right)$, and shortwave ( $\alpha_{\mathrm{SW}}, 0.4 \sim 2.1 \mu \mathrm{m}$ ), for a more detailed comparison of albedo.

The albedo obtained from SciML has the same spatial resolution as the geolocation data (MOD03), which is $1 \mathrm{~km}$, whereas the aircraft's pyranometers/albedometer have a significantly smaller footprint. As a result, when evaluating SciML models, the estimated albedo is collocated with the MODIS grid and the average value of about 170 measurements from each flight is mapped to a single MODIS pixel. With the MLCM (Chen et al., 2018), the pixels with cloud contamination are filtered, and only three surface types were kept in the validation dataset (i.e. sea ice, snow-covered sea ice, and water).

Finally, while the SciML-derived albedo is valid for surface observations, there may be a bias between it and the albedo measured at aircraft height. The Polar 5 and Polar 6 aircraft reached $3000 \mathrm{~m}$ height during the mission, and therefore, the albedo measurements were influenced by the entire atmospheric layer below the aircraft, resulting in a significant variance in albedo results. To account for the difference caused by the atmospheric constituents, we used the coupled RTM (Stamnes et al., 2018) to simulate the albedo of snow, bare ice, melt pond, and open water surface at three different levels: surface $\left(\alpha_{s}\right)$, low flight level $\left(\alpha_{l}, l=350 \mathrm{~m}\right)$, and high flight level $\left(\alpha_{h}, h=3000 \mathrm{~m}\right)$. Albedo ratios, $r_{l}=\frac{\alpha_{l}}{\alpha_{s}}$ and $r_{h}=\frac{\alpha_{h}}{\alpha_{s}}$, were calculated to determine the difference in albedo induced by the atmospheric layer below the flight height.

Figure 1 illustrates the aforementioned spectral and broadband albedos, as well as the ratios. There is greater influence of multiple scattering above the open water surface due to atmospheric components, particularly in the visible (VIS) range; the albedo at $h=3000 \mathrm{~m}$ is double that on the surface, whereas the presence of an atmosphere and aerosols results in a decrease in albedo over a bright surface. Among these, the reduction is particularly noticeable in the near-infrared (NIR) band, where air absorption results in a $4 \%$ and a $22 \%$ decrease in albedo at low and high levels, respectively. Similar simulation results were found by Jäkel et al. (2021a), using the Two-streAm Radiative TransfEr in Snow (TARTES) model (Libois et al., 2013). As can be observed, the difference between low-level and surface albedo is less than 5\%, whereas the difference between high-level and low-level albedo is significantly greater. As a result, we did not use aircraft observations taken above $350 \mathrm{~m}$ in order to improve the validation of the surface albedo retrieval.

With aforementioned pre-processing steps including geographic collocation and observational altitude restrictions, measurements from two days during the AFLUX campaign were partly from clear-sky, while the remainder were entirely from broken clouds (for a description of the AFLUX data, see Stapf et al. (2021b)), and seven flight transits from ACLOUD were retained. The MOSAiC campaign included fewer than 50 valid data points, and all obtained for broken cloud conditions. To eliminate errors caused by dense cloud cover, MOSAiC data were omitted from validation.

In all, the selected flight sections are depicted in Fig. 2. Up to four satellite images per day could be employed for retrieval and evaluation in the polar regions. When flight transits were compared to the percentage of cloud coverage $\left(f_{c}\right)$ for the 


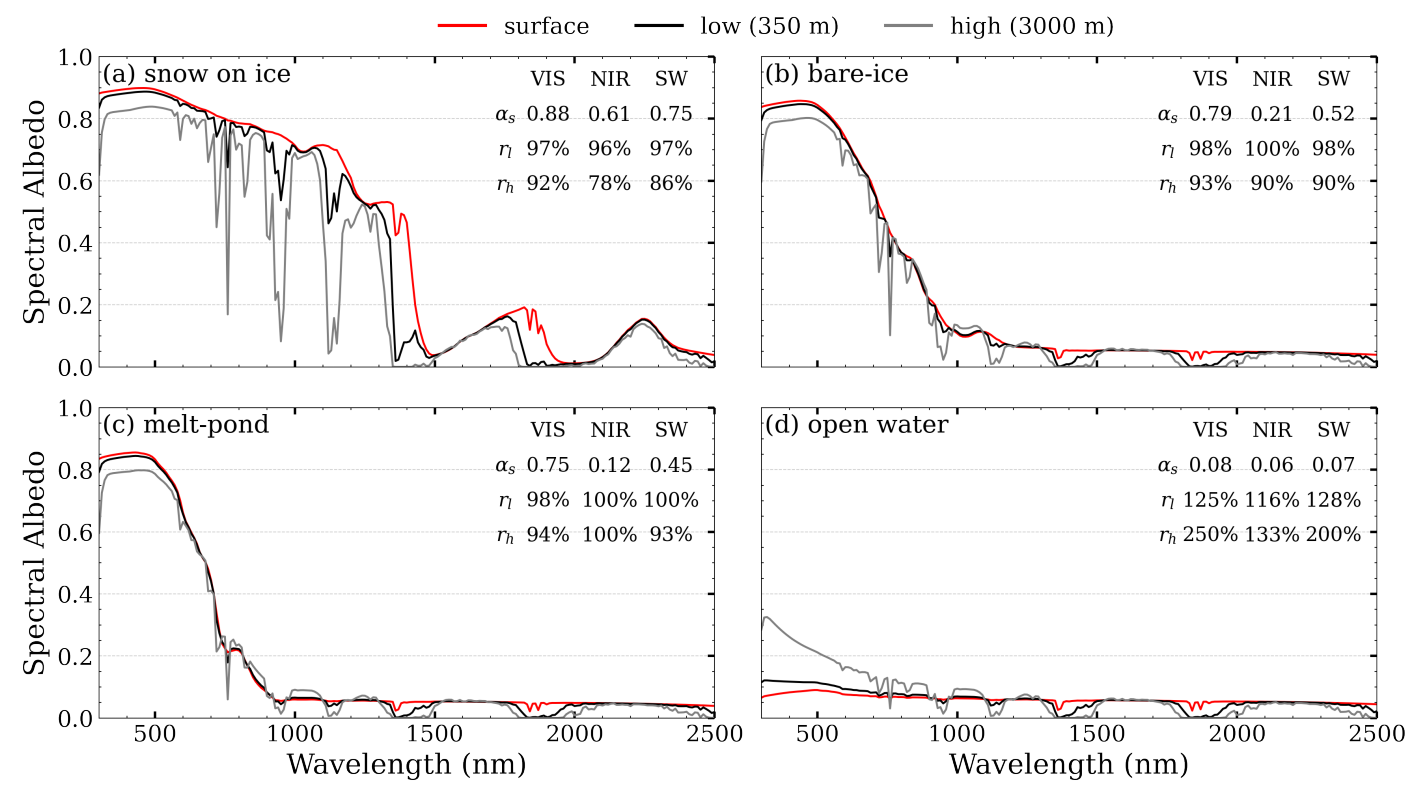

Figure 1. Spectral albedo computed by the RTM at various altitudes (350-m in black line, and 3000-m in gray line) and the surface (red line).

matching dates in the latitude-longitude range of flight operations (identified using the MLCM, Chen et al. (2018)), only seven days had clear-sky sea ice observations $\left(f_{c} \leq 90 \%\right)$. June 25,2017 had the lowest cloud coverage $\left(f_{c} \leq 30 \%\right)$ of them all. The MODIS transits that correspond to the aircraft operation time and $f_{c}$ are listed in Table A1.

By comparing the panels in Fig. 3, we may conclude that MLANN models are capable of producing satisfactory albedo outputs with low errors and high Pearson-r coefficients. Additionally, the agreement between the retrieved shortwave albedo and the pyranometer-measured albedo is better than with the albedometer; the regression line (marked in red) connecting the pyranometer-measured albedo and the retrieval almost completely overlaps the $(0,1)$ line, indicating a perfect one-to-one correspondence. Apart from the obvious advantage of having more measurements (i.e., twice the data size of data from the ACLOUD campaign with two aircraft and the addition of data obtained from the AFLUX campaign) for evaluation, another reason could be that the equipment has a lower uncertainty; the uncertainty of the "SMART Albedometer" was reported to be 7\%, whereas the pyranometer's uncertainty is less than 3\% (Gröbner et al., 2014; Ehrlich et al., 2019).

As illustrated in Fig. A1, the correlation coefficients for snow and water are relatively high across the wavelength ranges, whereas the correlation coefficients for sea ice are lower. The correlation coefficients for water are greater than 0.8 , those for snow are greater than 0.6, and those for sea-ice are less than 0.6. The reason is that in contrast to the more stable glacier, sea ice, particularly ponded sea ice, is more variable. The flight operations occurred between late May and late June, indicating the likelihood of intra-daily variation caused by pond development, pond drainage, and ice drift. For the days covered, the mean time discrepancy between MODIS transit and flight measurements is about two hours, with a maximum time difference of three to five hours ( $4 \mathrm{~h}, 4.85 \mathrm{~h}$, and $3 \mathrm{~h}$ for May 31, June 8, and June 25, respectively). Examination of the daily retrievals 


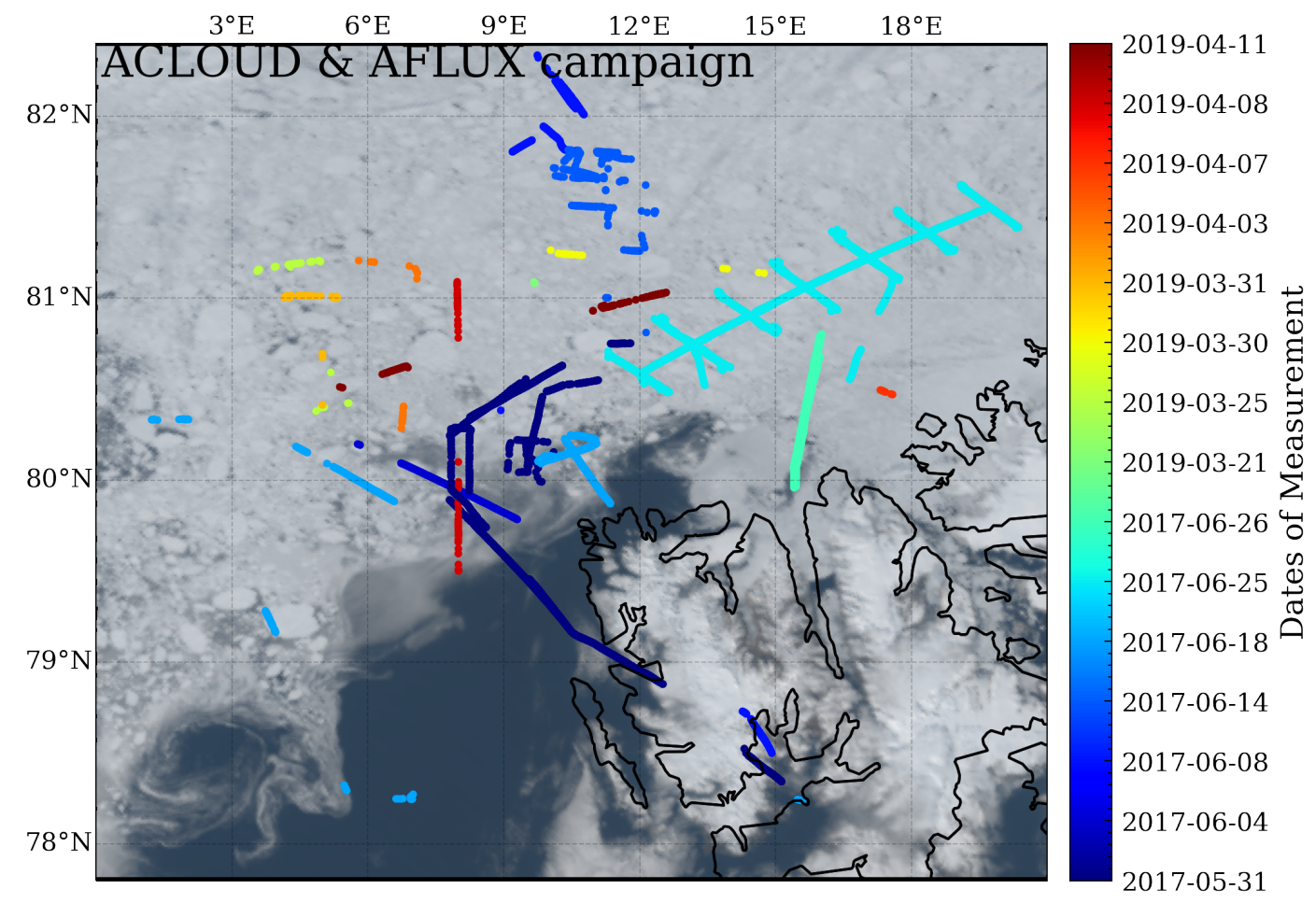

Figure 2. ACLOUD and AFLUX transits of selected flight segments from Polar 5 and Polar 6. In the background, the true color composite from June 25th, 2017 is shown; MODIS channels $645 \mathrm{~nm}, 555 \mathrm{~nm}$, and $469 \mathrm{~nm}$ are used as (R,G,B) bands for the true color RGB.

revealed that the three days with the widest temporal window also had the lowest agreement. When a time window of 1.5 hours was used for time restriction, a higher degree of agreement was found (Fig. 5).

Additionally, we observe that the highest inaccuracy occurs in the near-infrared band, with the error for white surfaces (sea ice and snow) being the most pronounced (around 15 percent over-estimation). Apart from the larger positive bias inherent in the SciML algorithm (as compared to the visible band), the disparity in NIR values could be caused by the following two factors:

(1) Measurement uncertainty: The albedometer's overall uncertainty in the near-infrared wavelength band is reported to be the greatest (Jäkel et al., 2021a).

(2) Error related to the flight height of the aircraft: On snow-covered sea ice, the height-induced error is $4 \%$ (lower than the surface), which increases the gap between the retrieval (of ground) and the measurements (of low-altitudes). In contrast, for open water, the near-infrared albedo at $350 \mathrm{~m}$ is $16 \%$ greater than that just above the ocean surface (refer to the RTM simulation findings in Fig. 1), which nearly cancels out the retrieval error. 

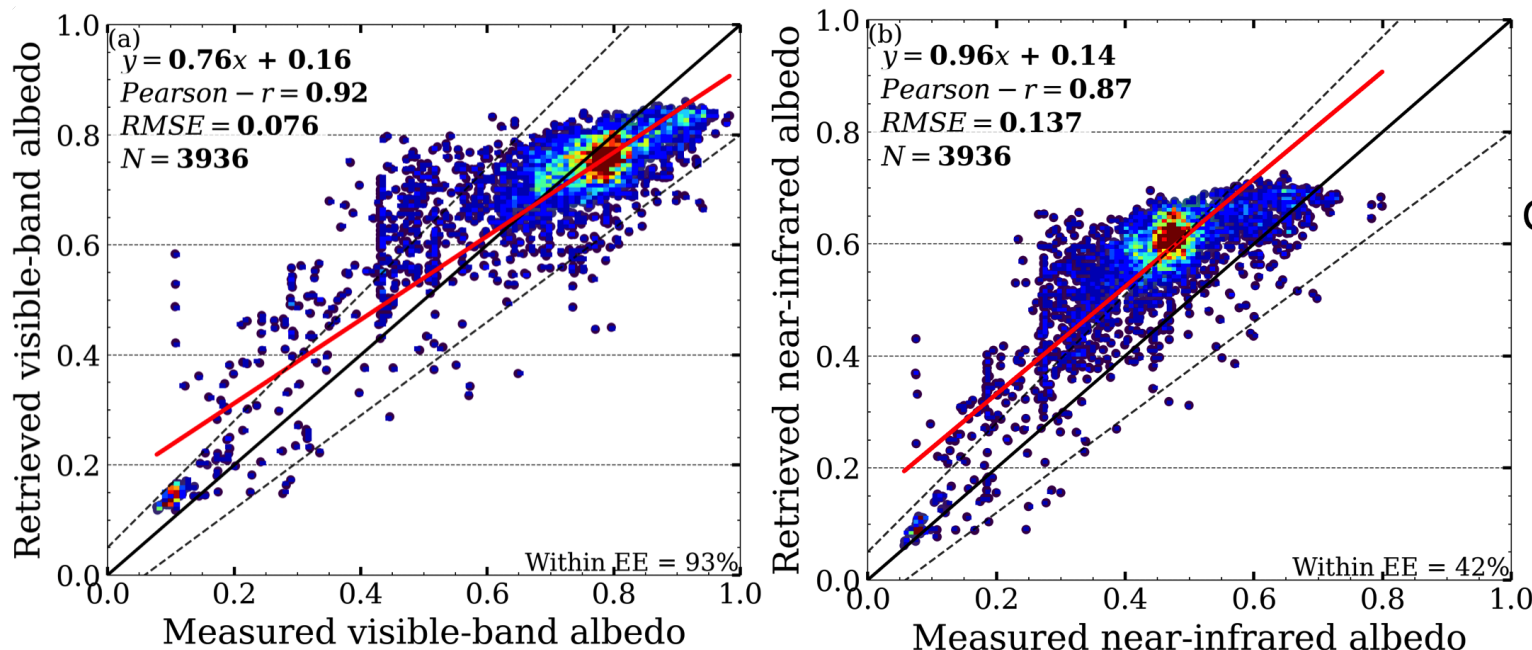

\section{Counts}
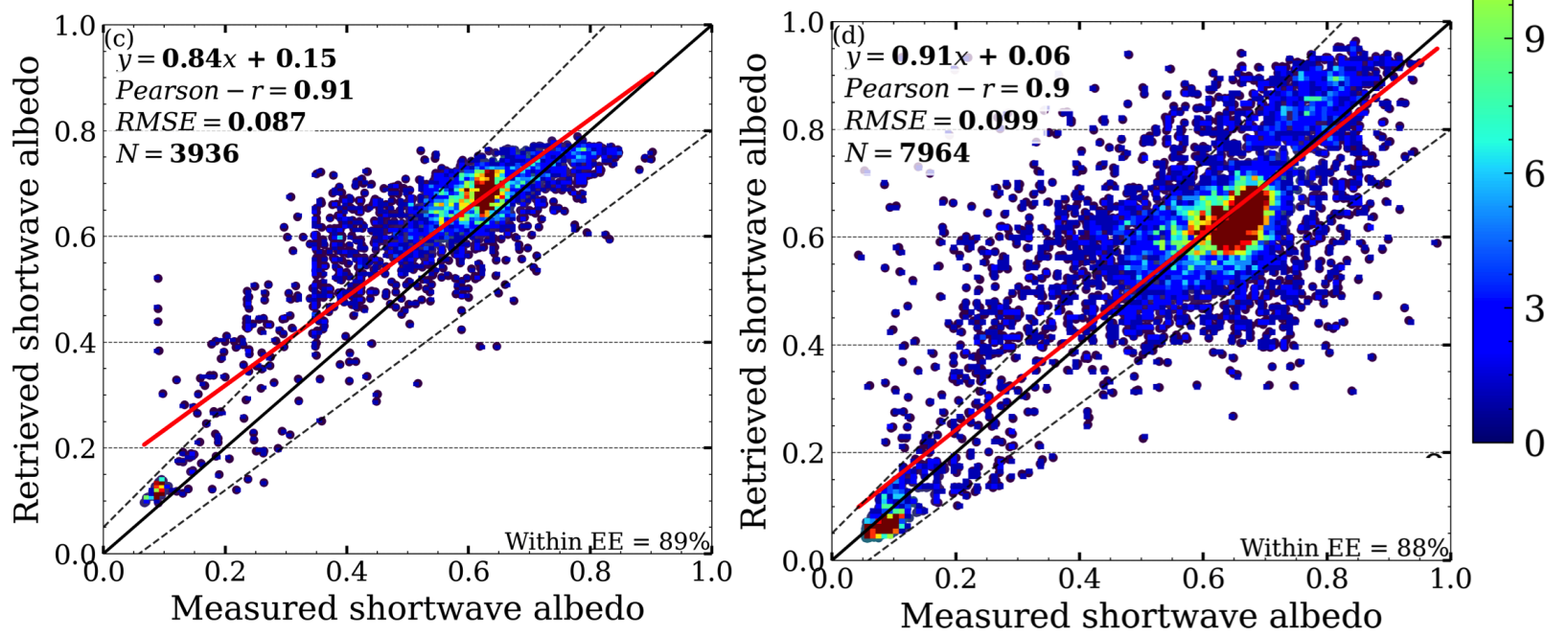

Figure 3. Correlation between ACLOUD-AFLUX albedo measurements and MODIS overflight. The comparisons with the albedometer in the VIS, NIR, and SW ranges are shown in panels (a)-(c), whereas panel (d) shows the comparison with the pyranometer. The color scheme indicates the density of the numbers. On the figure panels, the correlation equation $(\hat{y}=a \cdot y+b)$, Pearson $r$ coefficient $(r)$, root mean square error (RMSE), the percentage of data within a $15 \%$ expected error $\left(f_{E E \leq 15}\right)$, and number of pixels $(N)$ used to compute the statistics are provided. The red lines represent the linear correlation between $\hat{y}$ and $y$; the solid black lines represent $(0,0)-(1,1)$, and the dashed black lines represent the $15 \%$ error range. 
Furthermore, independent of the surface type or spectral range, all of the evaluations outlined above are prone to uncertainty due to equipment error, cloud contamination, surface metamorphism (drift and melt/refreeze), as well as differences in observation height, footprint, and solar zenith angle (SZA).

In the following discussion, we will break down and analyze the errors by their sources. The data were subjected to a more stringent temporal constraint of $\delta_{t}=1.5$-h in order to allow for a more precise characterization of specific sources of inaccuracy. Figure 4 depicts the $\%$ difference between the observed and retrieved shortwave albedo. Still, the percentage difference between the MLANN-estimated values and pyranometer measurements are smaller than those with albedometer measurements. Meanwhile, the error for the open-water surface (flight segments within the dashed red line) is significantly larger when compared to the albedometer data than when compared to the pyranometer data.
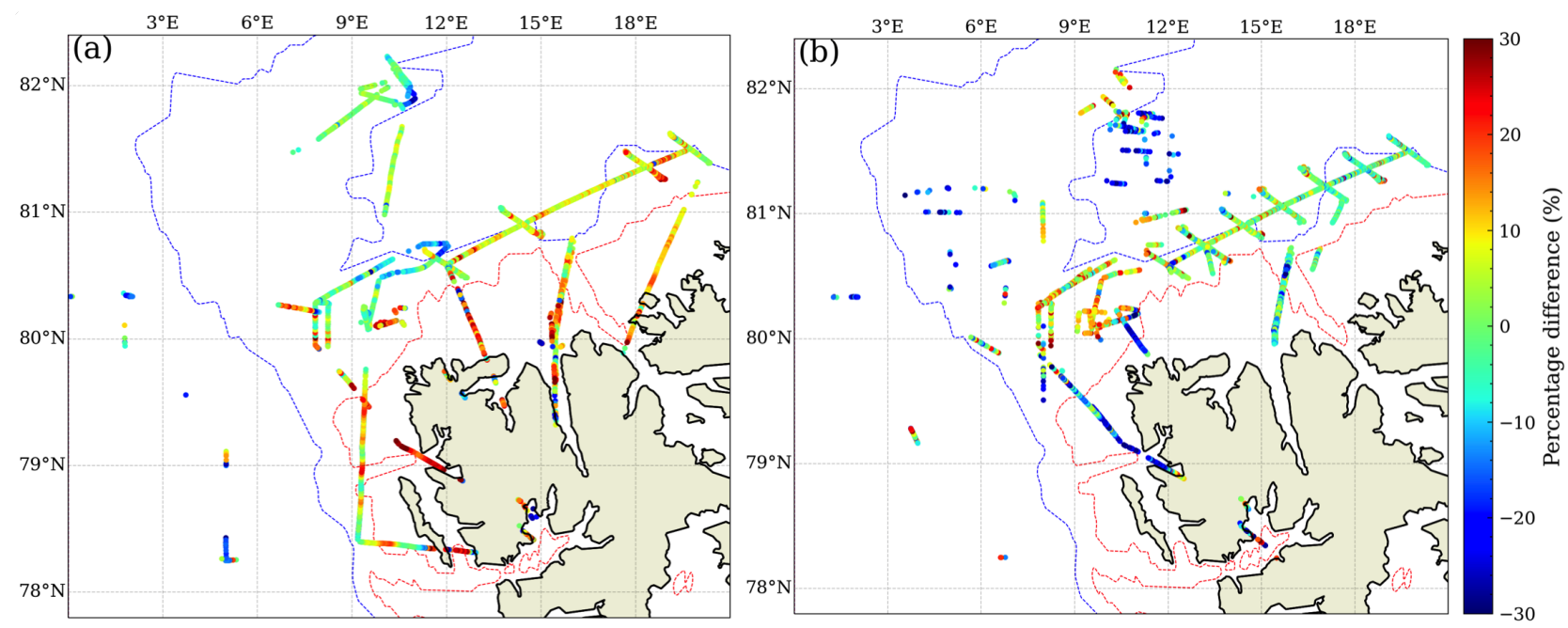

Figure 4. A map illustrating the percentage difference between the MLANN-estimated broadband albedo and the albedo measured in-situ using (a) the "SMART" albedometer, and (b) the pyranometer. To choose the matching MODIS retrieval, a tight time constraint of 1.5 hours $\left(\delta_{t} \leq 1.5\right.$-h) was applied. On the right, the colorbar indicates the scale of the $\%$ difference value for each dot. Additionally, red and blue dashed lines represent the 200-meter and 1000-meter isobaths. Each flight segment's dates are listed in Fig. 2.

\subsection{Distinction in the footprint of observation}

Due to the disparity between the aircraft and MODIS footprints, around 170 aircraft measurements were up-scaled to match one satellite pixel. According to prior research, an albedo line 100 meters long surrounding melt ponds would have a standard deviation of roughly 0.4 (Perovich, 2002), while the albedo of thin ice inside a grid cell would have a standard deviation of up to 0.29 (Lindsay, 2001). Due to the fact that measurements along the aircraft transit do not accurately reflect the area's average albedo (as determined by satellite sensors), the uncertainty introduced by different observation footprints (i.e. subpixel effects) 
is not negligible but difficult to quantify. On a homogeneous surface such as fresh snow, subpixel effects could be small, but for the heterogeneous surface consisting of a snow-ice-water mixture, the influence is large.

\subsection{Cloud contamination effects}

While cloud screening eliminates cloudy pixels in satellite data, data acquired during airplane flights are not corrected for cloud cover. Given that more than one-third of the operational spatial range is obscured by clouds, it is possible that some pixels labeled as 'clear sky' by the MLCM are cloud-contaminated as a result of (i) a time mismatch between the MODIS overpass and aircraft data collection, or (ii) simply imperfect cloud screening. Multiple reflections between the surface and cloud base would introduce uncertainty into the albedo measured by the airplane.

As illustrated in Fig. 5, the agreement is negatively correlated with cloud coverage, with the exception of panel (b). On June 8, 2017, the date depicted in panel (b), a considerable decrease in temperature and an increase in liquid water vapor (IWV) were recorded (Wendisch et al., 2019). Following a day of dense cloud cover, the surface temperature measured on ice floe camps increased by 2 degrees on June 10, 2017 (Barrientos Velasco et al., 2018). A Magna probe (Sturm and Holmgren, 2018) recorded that snow depths on the ice floe on June 14 were down to $22 \pm 18 \mathrm{~cm}$ (with $32 \%$ of data below $10 \mathrm{~cm}$ ), while on June 5 the snow depth was $37 \pm 24 \mathrm{~cm}$ (with $9 \%$ of data below $10 \mathrm{~cm}$ ) (Jäkel et al., 2019). These data indicate that the surface conditions changed radically around June 08 , which possibly led to the larger mean absolute error (of 0.122). The mean absolute error is all minor on the three days with significantly less cloud cover (panels a, $\mathrm{d}$, and e). The best agreement occurs on June 25, when an analysis of 2245 accessible MODIS pixels reveals an error of only 0.047 ; 96 percent of the data are within an error of $15 \%$.

The spatial overlay of observations from June 25, 2017 on a retrieval image utilizing MODIS's 12:45 UTC transit is shown in Fig. 6. Snow, open water, and bare ice albedo values are all within acceptable limits and are in good agreement with albedometer/pyranometer determinations.

Fortunately, during the campaign, the above-mentioned latitude-longitude range experienced three consecutive days of clear skies, from June 24 to June 26, 2017. The data from four MODIS overflights per day (see Table A1) can be used to determine changes in surface albedo caused by changes in solar zenith angle and surface metamorphism.

\subsection{Albedo variations caused by changes in the solar zenith angle}

Visual examination of the RGB images of the eight MODIS transits from June 24 to June 25 revealed no apparent ice drift during the two days. Following that, we used the MLCM to filter out pixels that were tainted by cloud during any of the four MODIS transits on June 25, allowing us to detect cloud-free sea ice, snow, and water surface. In other words, assuming no ice drift, the changes in the albedo value over the course of the four satellite transits are caused by either surface metamorphism or a changing solar zenith angle.

The probability density functions (PDFs) of the surface albedo in the region shown in Fig. 6 were produced using the selected data (Fig. 7(a)). A Gaussian kernel probability density (Turlach, 1993) was used to estimate the PDF. The probability of albedo values falling within the interval $\mathrm{P}(a<x \leq b)$ is measured by subtracting the two integral values $\mathrm{P}(a<x \leq b)=$ 

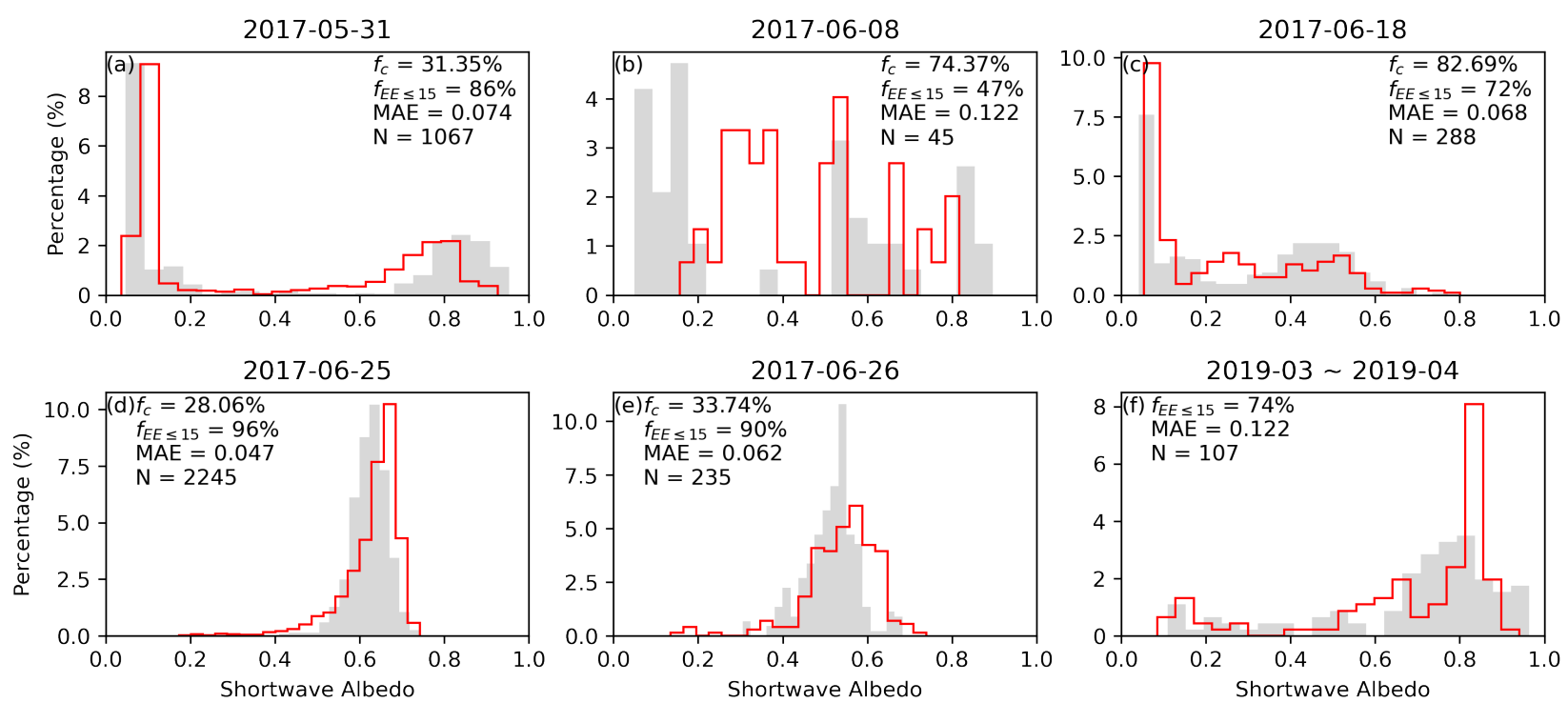

Neural-network retrieved shortwave albedo

Campaign-measured shortwave albedo

Figure 5. Histograms of the shortwave albedo measured during the cloud-free ACLOUD-AFLUX flights (red columns) and the MLANN model's corresponding retrieval (gray columns). To choose the matching MODIS retrieval, a tight time constraint of 1.5 hours $\left(\delta_{t} \leq 1.5-\right.$ h) was applied. The dates are displayed at the top of each panel. Additionally, the upper right corner displays the cloud fraction $\left(f_{c}\right)$, the percentage of data within $15 \%$ expected error $\left(f_{E E \leq 15}\right)$, the mean absolute error (MAE), and the number of pixels for each evaluation (N). Due to a lack of appropriate data, all AFLUX measurements were combined together for examination, as illustrated in panel (f).

$F_{x}(b)-F_{x}(a)=\int_{a}^{b} f(x) d x$, where $F(x)$ is the cumulative density function (CDF) and $f(x)$ is the PDF. The area between the PDF-curve and the $x$-axis is equal to one (Scott, 2015). The bimodal distribution with one mode at 0.1 and the other at 0.65 indicates that the most prevalent surface types are water and snow-covered sea-ice, with bare ice accounting for a small portion of the data.

We noted the difference in SZA over the four MODIS transits, from 55 59 at 11:05 UTC to a higher value of 61 65 at 16:00 UTC, and the difference increased the albedo for snow and water by $6 \%$ and $30 \%$, respectively, while the values on the bare-ice surface remained relatively stable (5\% fluctuations).

The variations in albedo caused by increasing SZA were investigated in RTM simulations (see insert table in Fig. 7(b)). The relevant parameters for the simulation are: snow thickness $h_{s}=0.2 \mathrm{~m}$, effective grain size of snow $r_{e}=100 \mu \mathrm{m}$, pond depth $h_{w}=0.1 \mathrm{~m}$, and black carbon impurity fractions for snow and ice $f_{b c}=1.0 \times 10^{-7}$. Although the difference in broadband albedo values indicates that the snow, ice, and water conditions in the RTM simulations do not match the surface conditions at this location, they may serve as a reference for the portion of the albedo difference caused by SZA, which is $2.7 \%, 50 \%$ and $4 \%$ for snow-covered ice, water, and bare-ice, respectively. With these numbers in mind, we can conclude that the lower 

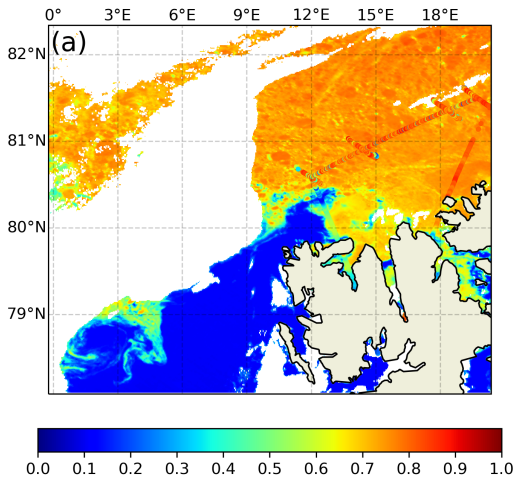
Visible-band $(400 \sim 700 \mathrm{~nm})$ Albedo

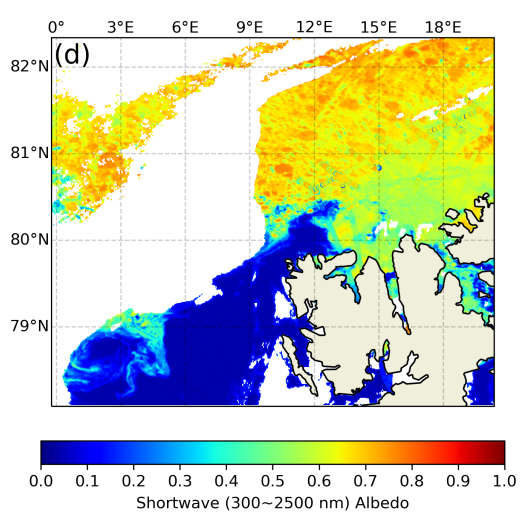

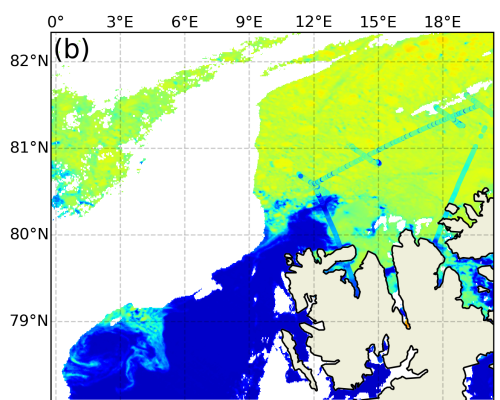
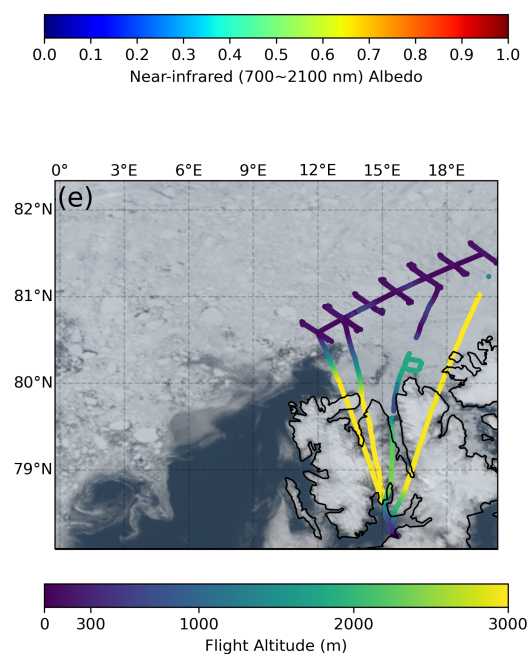
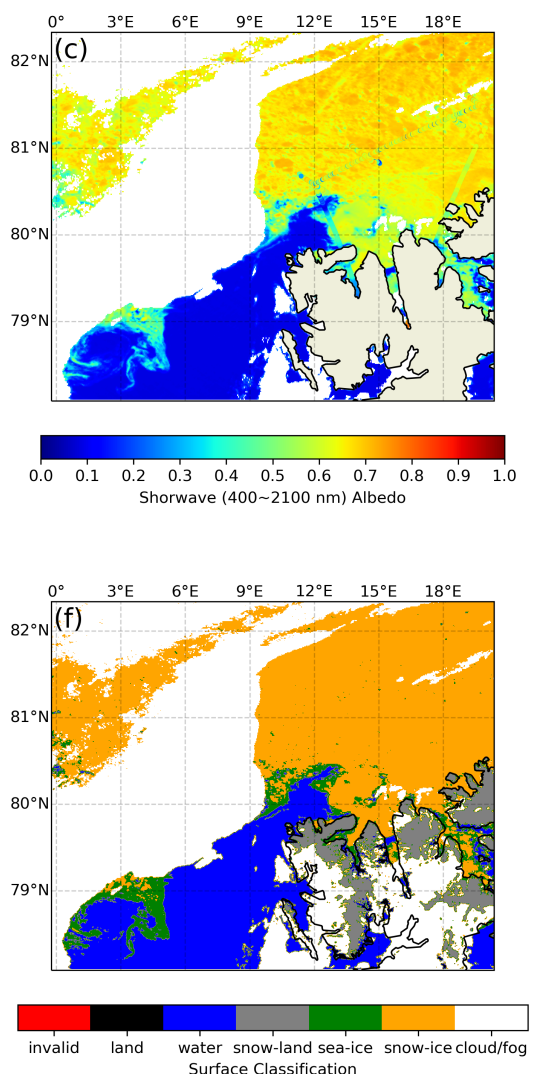

Figure 6. (a)-(c): spatial overlay of albedometer measurements on top of the MLANN-derived albedo in the VIS, NIR, and SW ranges from 12:45 UTC, June 25 2017; (d): spatial overlay of pyranometer measurements on the MLANN-derived SW albedo; (e): spatial overlay of aircraft altitudes on the true color composite; and (f): surface classification results. Cloud-contaminated pixels (shown in white in (f)) were removed during the retrieval.

variance in snow/ice surface albedo (despite increasing SZA) and the less noticeable increase in water albedo are both related to surface melting.

\subsection{Changes in albedo as a result of surface metamorphism}

To analyze the variation in albedo induced by surface metamorphism, we used the albedo derived from eight MODIS overflights over a two-day period, selecting 'consistently clear pixels' using the same approach as stated previously. The pixels that have been filtered out due to cloud cover happen to be snow cases. As a result, the following analysis focuses on the phase transitions at the marginal sea ice zone, which is a system composed of bare ice thicker than $30 \mathrm{~cm}$ (typical albedo values between 0.4 and 0.5, Brandt et al. (2005); Petrich and Eicken (2009)), melt ponds (typical albedo values between 0.2 0.4, Grenfell and Maykut 

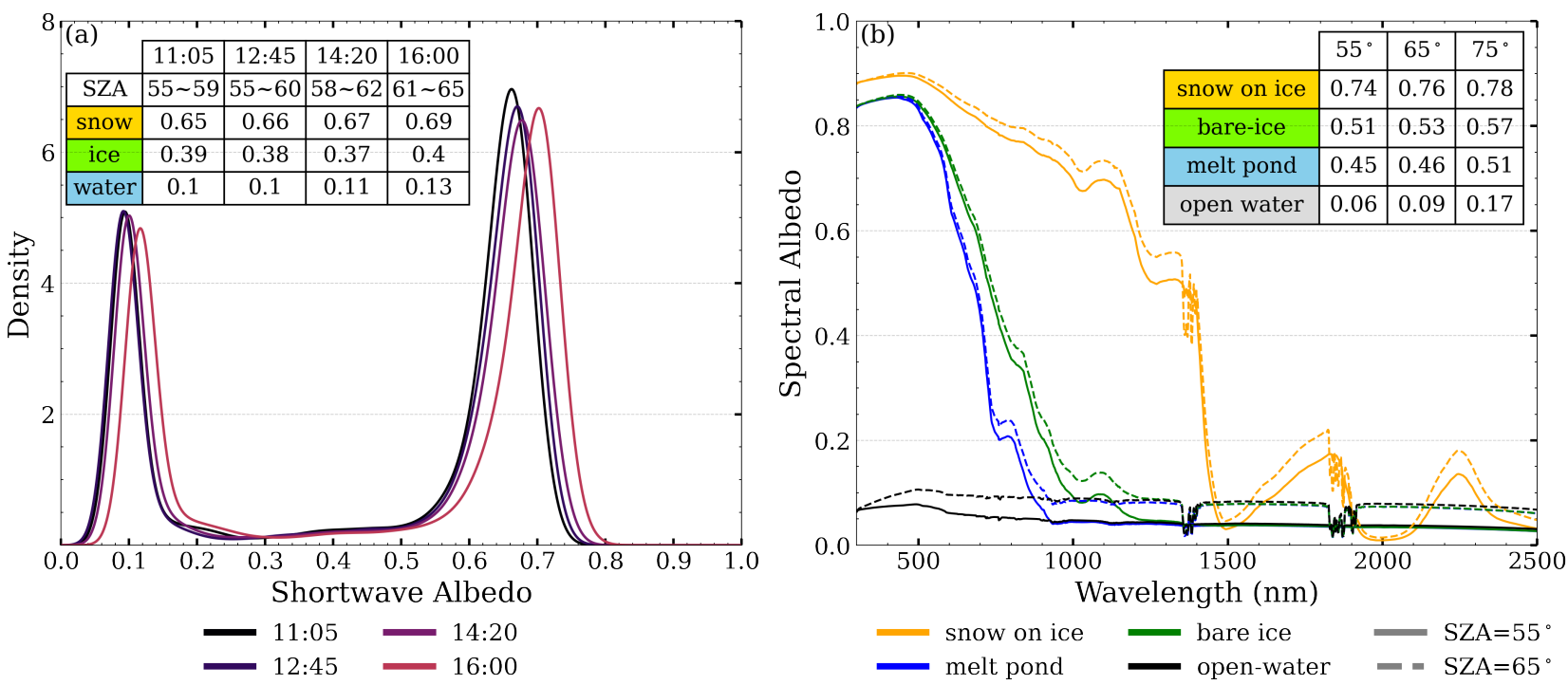

Figure 7. (a) Probability density curves of albedo on June 25. The colors denote the retrievals from several MODIS overflights. The average albedo estimated for each surface is provided in the upper left table, along with the solar zenith angle (SZA) ranges. (b) RTM-simulated spectral albedo of snow, melt-pond, bare-ice and open-water surfaces; dashed and solid lines indicate spectral albedo with varying SZA. The table to the right shows the calculated shortwave albedo of each (surface, SZA) pair.

(1977); Grenfell and Perovich (1984); Grenfell (2004); Petrich and Eicken (2009)), and open water (typical albedo below 0.2, Toyota et al. (1999); Petrich and Eicken (2009) ).

Interestingly, the decrease in albedo of a single fixed pixel over about 24 hours can be as significant as -0.4 and -0.3 , respectively, when evaluated in the afternoon and when the two values based on morning overflights are subtracted. The histograms appear to be similar in shape when comparing the distributions of $\alpha_{24}$ and $\alpha_{25}$ at the same SZA (i.e. compare the columns). As no apparent ice drift was observed and the location was at the intersection between open water and sea-ice regions, this circumstance indicates that the surface was undergoing intermittent melting and refreezing, akin to the situation of a polynya.

\subsection{Comparison of SGLI and MODIS retrievals}

Thus far, the focus has been on MODIS retrievals. In this section, the SGLI-sensor retrievals will be compared to the MODISderived results using data from the AFLUX campaign.

Frequently, fog (sea smoke) forms above sea ice and polynyas (Vihma et al., 2014). On April-08 2019, data taken south of $80.6^{\circ} \mathrm{N}$ were in such a condition. On April-11, a thick cloud with a sharp edge moved from $15^{\circ} \mathrm{E}$ at 5:50 UTC to $7^{\circ} \mathrm{E}$ at $12: 25$ UTC (Stapf et al., 2021b). As seen in the RGB and surface classification images (Fig. 9), the fog from April-08 and the cloud from April-11 was correctly identified by the MLCM for both sensors. 

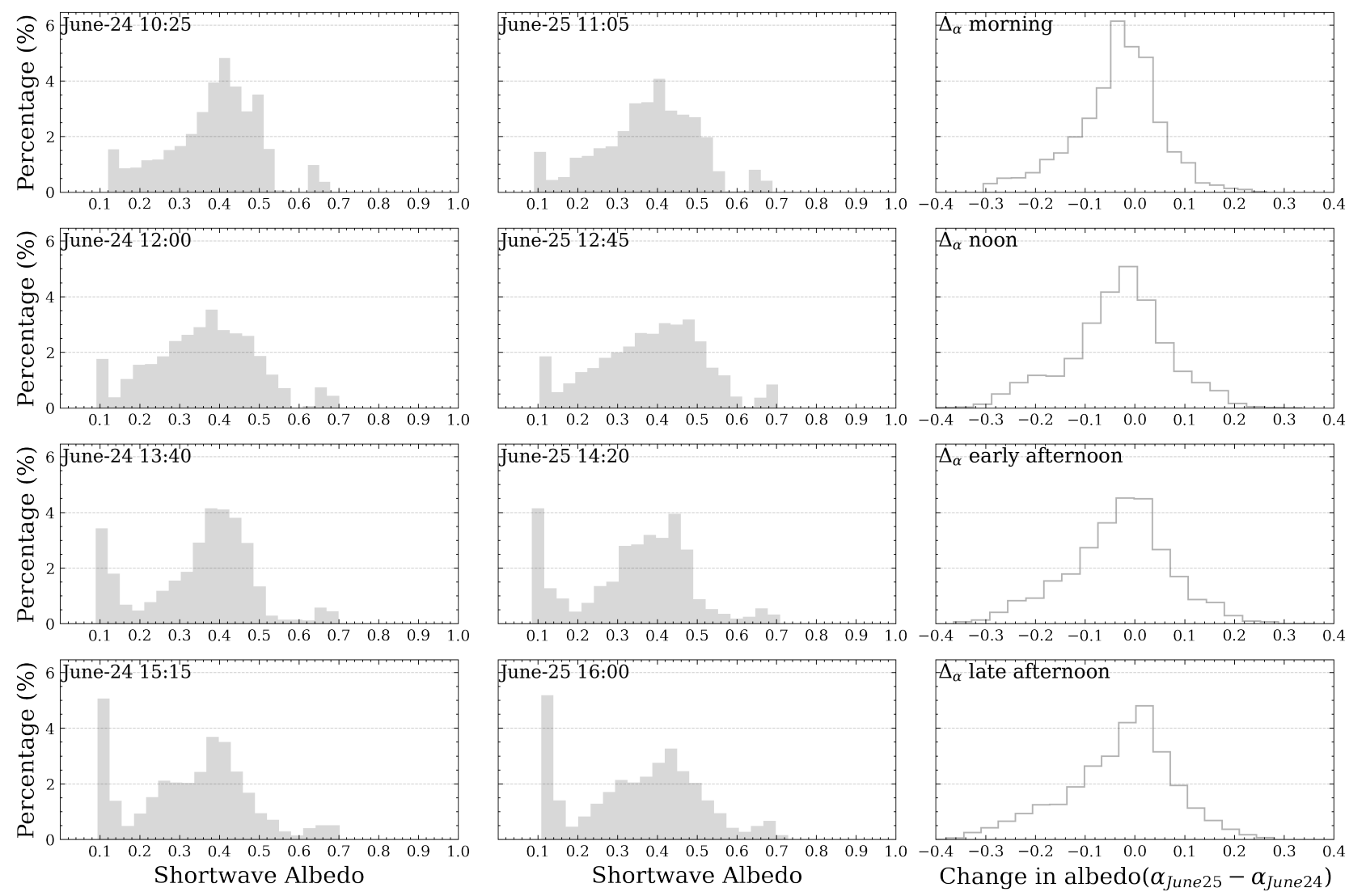

Figure 8. Histogram of the distribution of albedo values observed during the eight MODIS overflights on June $24 \sim 25$. The albedo histograms for June $24\left(\alpha_{24}\right)$, June $25\left(\alpha_{25}\right)$, and the difference $\left(\Delta_{\alpha}=\alpha_{25}-\alpha_{24}\right)$ are shown in the columns from left to right. From top to bottom, the rows represent the four satellite overpasses that occurred throughout the day: in the morning, at midday, in the early afternoon, and in the late afternoon.

On April 11, the cloud-free area was seen to have a hazy atmosphere (Stapf et al., 2021b), and RTM models showed a thick aerosol optical depth of 0.065 (wavelength unspecified). The MLCM also detected the haze, which was classified in Fig. 9 as 'cloud/fog'. Figure 9 indicates that, even with the impact of cloud/fog/hazy atmosphere, the SGLI- and MODIS-retrieved albedo values $(\alpha)$ for difference surface types are within reasonable ranges: melt pond $(\alpha \leq 0.3)$, bare sea ice $(\alpha \approx 0.6)$ and sea ice with snow coverage $(\alpha \geq 0.7)$. When compared to data from low-level $(\leq 350 \mathrm{~m})$ aircraft at the same location and to cloud-free MODIS retrievals (Fig. 9), the values are largely consistent.

The scatter plot in Fig. 10 illustrates the correlation between the measured and retrieved albedo (under clear-sky conditions on April 8) using SGLI-channel and MODIS-channel radiances. Both results were derived with the same retrieval methods as those outlined in Section 2. For retrieval using SGLI data, $82 \%$ of the data were under the $15 \%$ expected error (EE), demonstrating a higher degree of agreement than the results produced from MODIS radiance data for this date. Correlation 

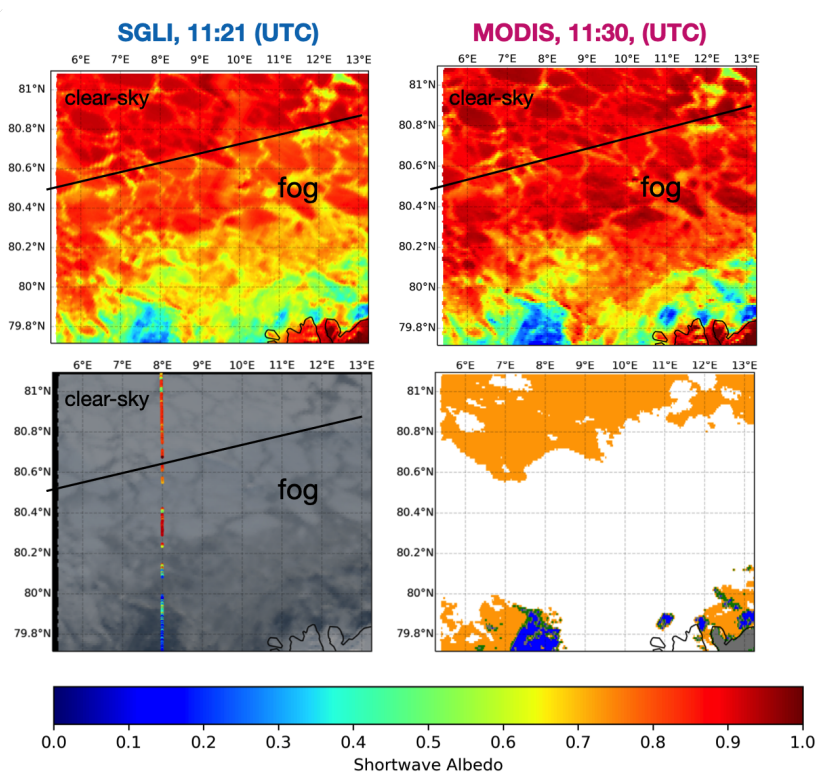
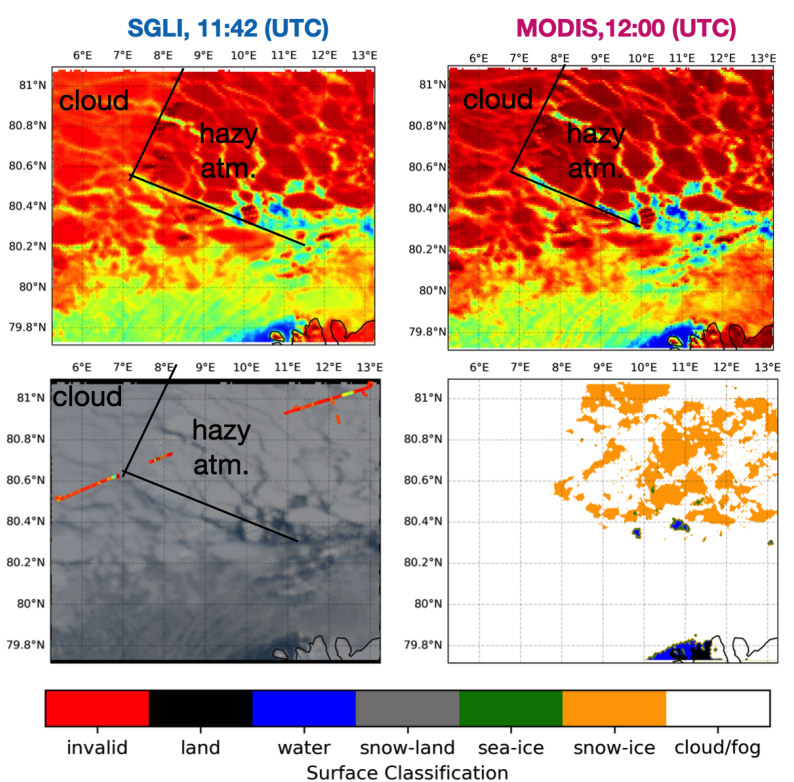

Figure 9. Albedo-retrieval maps, RGB maps, and surface classification maps from April 08, 2019 (left) and April 11, 2019 (right). The topleft column represents the albedo values retrieved with the SGLI sensor, the top-right column represents the albedo values retrieved with the MODIS sensor, the bottom-left column represents the spatial overlay of surface albedo measurements made on low-level ( $\leq 350 \mathrm{~m})$ flights (dots) on true color composite images, and the bottom-right column represents the surface classification results. The black lines represent the distinctions between various atmospheric conditions.

coefficients of 0.984 and 0.892 , as well as RMSE of 0.082 and 0.136 , indicating that combining RTM and MLANN for cryosphere surface albedo retrieval can produce satisfactory results.

To summarize, we evaluated the MLANN model using in-situ measurements. The uncertainties associated with the evaluation were explained in detail, per source of error, in order to evaluate their impact. Despite these uncertainties, the current technique for albedo retrieval, which is based on (1) an AccuRT-generated SD and (2) a SciML/MLANN model trained using the SD as prior knowledge, can indeed produce reasonable albedo outputs, with a mean absolute error of 0.046 under clearsky conditions. Following that, in the SGLI-to-MODIS comparison, we demonstrated the capability of the SciML/MLANN technique and the possibility of using the same framework to other satellite sensors that measure similar radiance data.

\section{Comparison of the retrieval product with the existing methods}

In this section, the MLANN-albedo retrievals using MODIS-channel radiances are compared with the two MPD-based products (derived using MERIS and OLCI sensors) as well as with the MCD43 product (derived using MODIS-channel reflectances). A brief description of the relevant products and sensors are provided in Sections 1 and 2. 
(a) 1

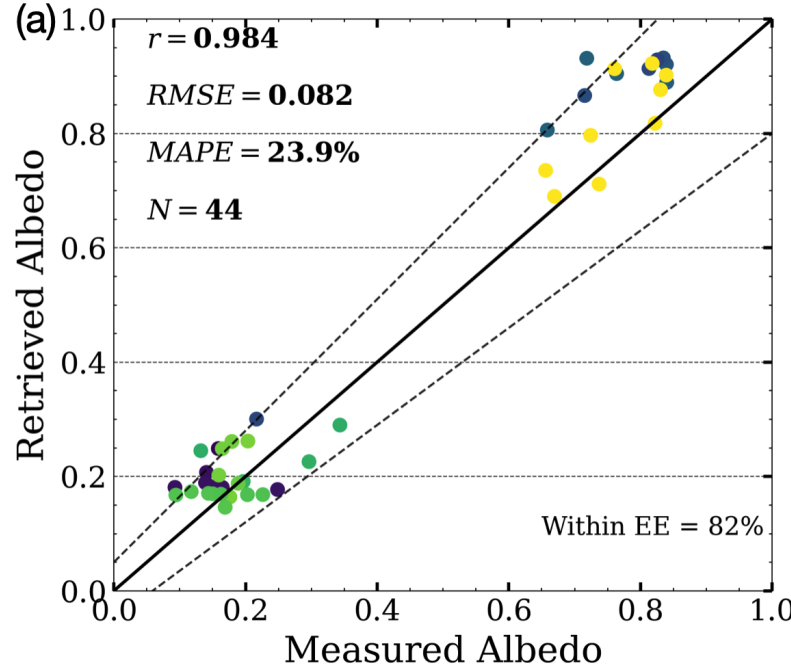

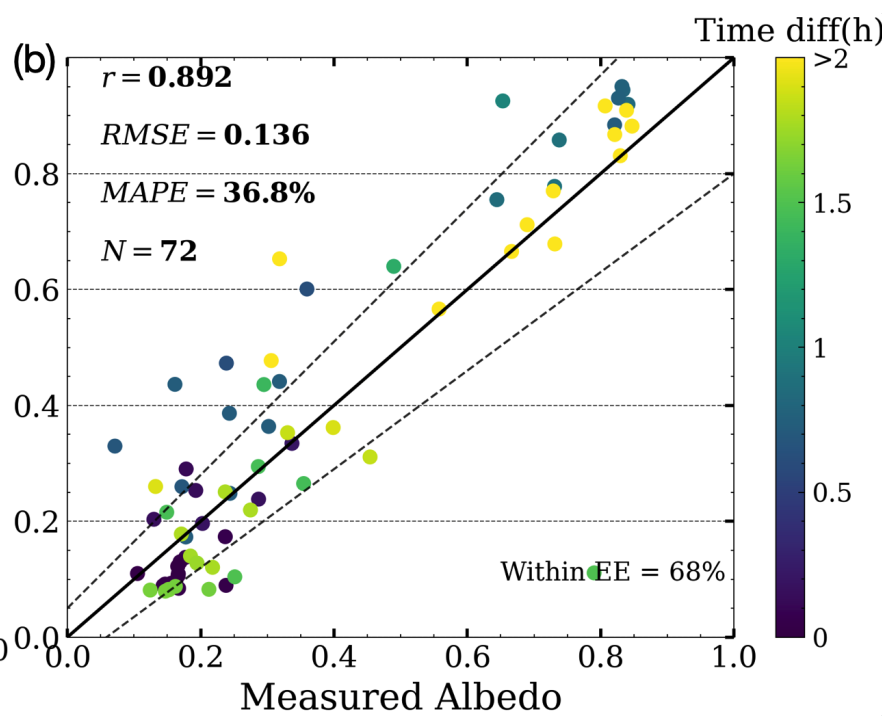

Figure 10. Correlation between shortwave albedo measurements from the AFLUX campaign and satellite overflight (SGLI (a), and MODIS (b)), April-08 2019. The color indicates the time interval between campaign measurements and satellite overpass. On the figure panels, the Pearson $r$ coefficient $(r)$, root mean square error (RMSE), mean absolute percentage error (MAPE) and the number of pixels (N) used to calculate the statistics are provided.

\subsection{Comparison with the MCD43D49 51 BSA products}

The MCD43D products, with 1-km spatial resolution, are the successors to the MCD43B products. The retrievals are carried out daily, using kernel weights that best represent the majority of situations across the 16-day period, with the day of interest emphasized. MCD43D49 51 correspond to the Black Sky Albedo (BSA) for the visible (0.3 0.7 $\mu \mathrm{m}$, VIS), near infrared $(0.7 \sim 5.0 \mu \mathrm{m}, \mathrm{NIR})$, and shortwave $(0.3 \sim 5.0 \mu \mathrm{m}, \mathrm{SW})$ bands, while MCD43D59 61 correspond to the White Sky Albedo (WSA) for the three broadband ranges (Schaaf and Wang, 2015b).

Due to the fact that MCD4 is a land-albedo product; only a small amount of sea ice surface albedo is available near the shore (in the 'shallow ocean' zone denoted by the BRDF/Albedo Quality Product, MCD43A2, (Schaaf and Wang, 2015a)). While prior research have validated the albedo product for glacier, tundra, and snow-covered land surfaces, the small amount of sea ice albedo on the shallow ocean has not been validated previously (Ren et al., 2021; An et al., 2020; Pope et al., 2016; Wang et al., 2012). Using ACLOUD-campaign measurements, the MCD43's reliability in the sea ice zone may be assessed.

On the same days, Figs. 11 and 12 compare the MLANN-derived broadband albedo values utilizing MODIS TOA radiances (i.e. MOD021KM) as input to the MCD43-derived BSAs. The MLANN-derived albedo values represent the average of all available clear-sky pixels observed across four MODIS transits within the day, whereas the MCD43 product is representative of the albedo at local noon (Stroeve et al., 2005). Therefore, values from the MCD43 product are expected to be slightly lower than the MLANN results due to the relatively lower solar zenith angle $\left(52 \sim 55^{\circ}\right)$. We need to highlight that the two 
https://doi.org/10.5194/tc-2021-397

Preprint. Discussion started: 18 January 2022

(c) Author(s) 2022. CC BY 4.0 License. $5 \mu \mathrm{m}$, respectively) and with different albedo assumptions (BSA and blue-sky albedo, for MLANN-albedo and MCD43-albedo, respectively). All albedo maps include superimposed SMART albedometer measurements from the ACLOUD campaign (Jäkel et al., 2018) as a 'ground truth' reference.

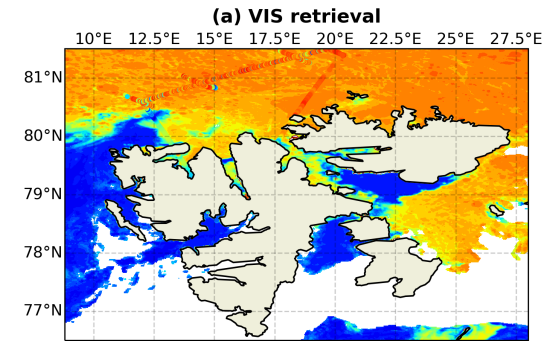

(d) MCD43D49 (VIS,BSA)
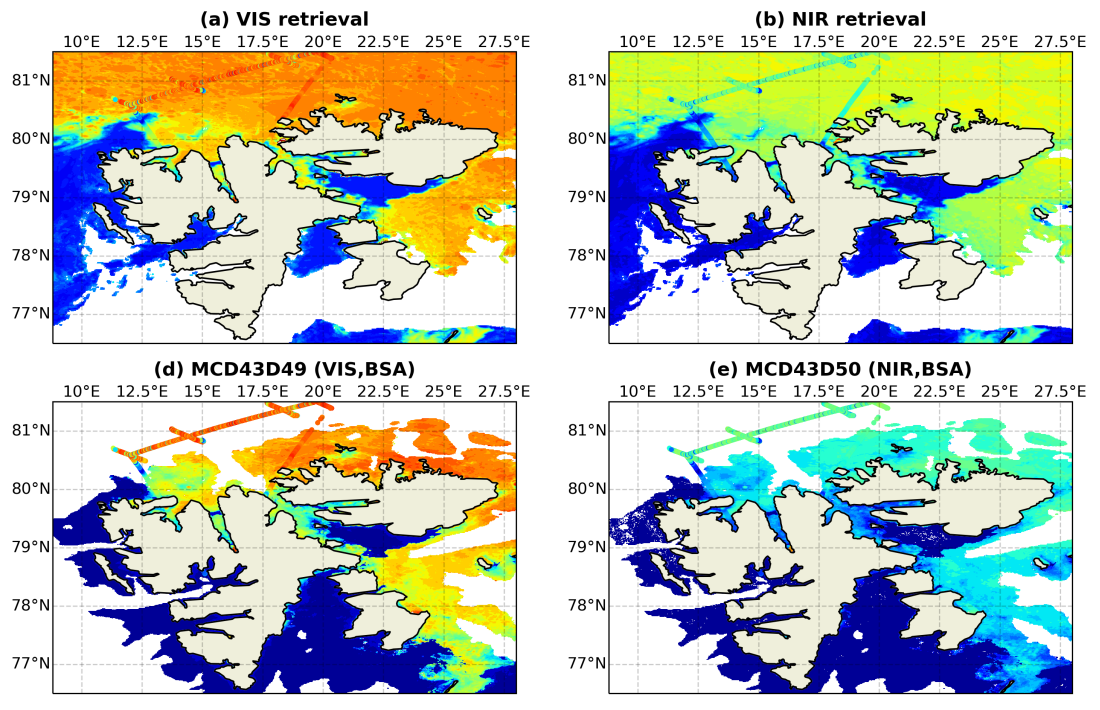

(b) NIR retrieval
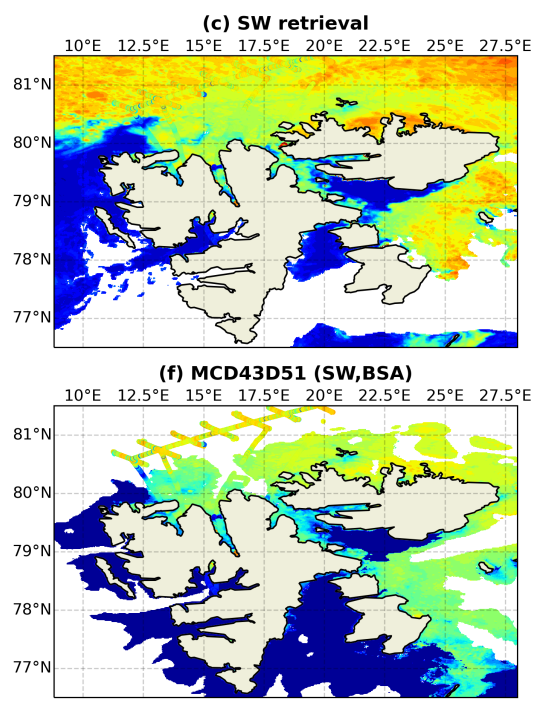

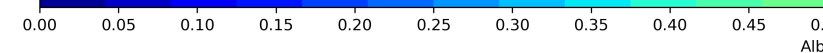

Figure 11. Albedo-retrieval maps on June 25, 2017 in the shallow ocean region near Svalbard. The albedometer measurements from the ACLOUD campaign are superimposed over the retrieval maps in each panel. Note that both low- and high-level flight measurements are included. (a)-(c): the visible, near-infrared, and shortwave (VIS, NIR, SW) albedo values derived using the MLANN-albedo product and MODIS radiance data; (d)-(f) the three broadband black-sky albedo values (BSAs) derived by MCD43D49-51. The empty regions in panels (a) to (c) correspond to cloud coverage throughout the day on June 25, 2017, whereas the empty regions in panels (d) to (f) correspond to ocean areas where MCD43 does not provide retrievals.

In the shallow ocean area, comparisons of MCD43-albedo and MLANN-albedo with measurements showed equally-good agreement in the VIS and SW ranges. As described in Section 3, the MLANN-derived NIR albedo on snow and sea-ice is about 15\% greater than measurements, whereas the MCD43-derived NIR albedo has a better agreement with data in the NIR band.

Because the BRDF is calculated using observations from a 16-day window, the MCD43 result cannot adequately capture daily albedo variations. One example is its failure to detect the opening of a melt pond north of Svalbard on June 25 and 26, located at $15^{\circ} \mathrm{E}, 80^{\circ} \mathrm{N}$. According to the eight RGB MODIS transit images (not shown), the melt pond began to open at 12:45 UTC on June 25, 2017, and by 15:05 UTC on June 26, 2017, the ice underlying the pond had entirely melted, leaving some bare sea ice (as categorized by the MLCM, Chen et al. (2018)) surrounding the open water. While MCD43 could not identify 
https://doi.org/10.5194/tc-2021-397

Preprint. Discussion started: 18 January 2022

(c) Author(s) 2022. CC BY 4.0 License.

(a) VIS retrieval

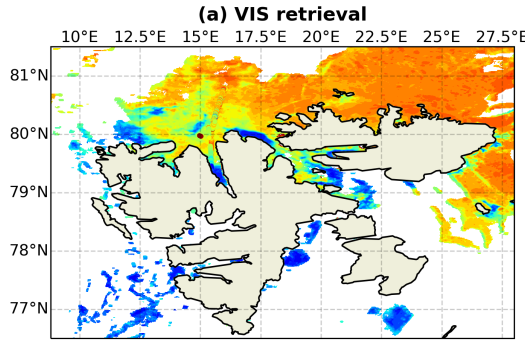

(d) MCD43D49 (VIS,BSA)

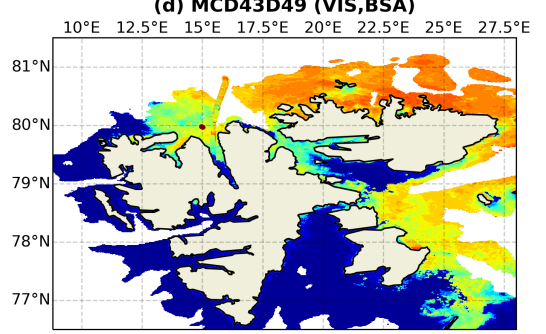

(b) NIR retrieval

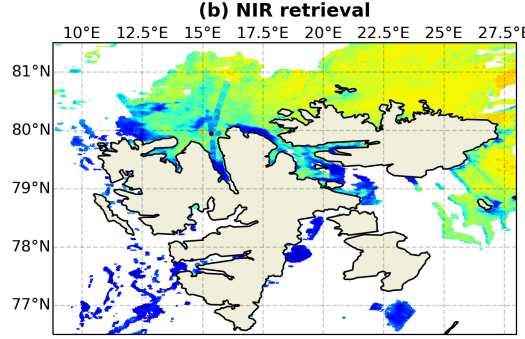

(e) MCD43D50 (NIR,BSA)

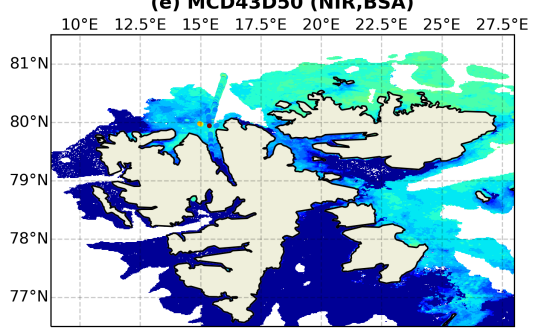

(c) SW retrieval

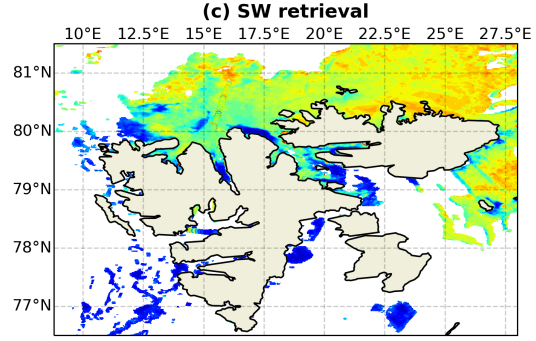

(f) MCD43D51 (SW,BSA)

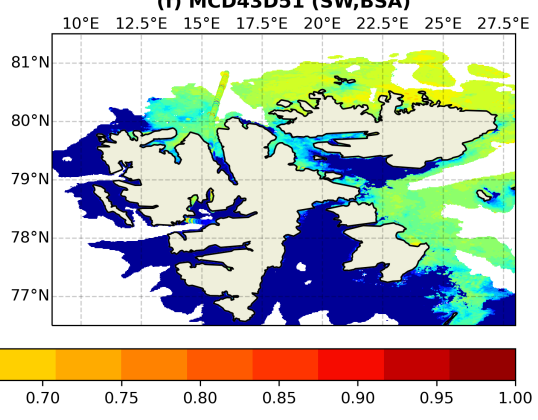

Figure 12. Albedo-retrieval maps, similar to Figure 11 but on June 26, 2017

this opening, the daily averaged MLANN-albedo indicates the snow and ice melting that resulted in the formation of a small open water region.

Another point to emphasize is the lower albedo values obtained by MCD43 on snow-covered ice when compared to the MLANN results, as demonstrated by the areas north and south of Nordaustlandet (near $22.5^{\circ} \mathrm{E}, 80.5^{\circ} \mathrm{N}$ and $25^{\circ} \mathrm{E}, 78.5^{\circ} \mathrm{N}$, respectively). While there are no direct measurements to verify these values, we note that the underestimation of snow-covered area has been mentioned in several previous studies. For example, Stroeve et al. (2005) discovered that the MCD43 retrieval for snow-covered Greenland Icesheet (with an albedo greater than 0.7 ) has a -0.05 bias when compared to ground-based measurements. Similarly, An et al. (2020) observed underestimation when the albedo is greater than 0.4 for ice caps. For the particular case observed on these two days, the main reason is the extensive melting during the warm period (Knudsen et al., 2018).

Although the MCD43D V6.0 products have been adjusted to better capture shorter-term albedo variations through adjusting the BRDF weighting scheme to emphasize the BRDF of the day of interest inside the 16-day sliding window, by examining the Quality Product (i.e. MCD43A2), we found a much higher 'BRDF albedo uncertainty' marked in the melting-snow areas as compared to the surrounding open-water. According to Lucht and Lewis (2000); Wang et al. (2012), the uncertainty can be related to fluctuations in surface properties, atmospheric correction errors, high solar zenith angle $\left(>65^{\circ}\right)$, and cloud detection during snow melt, among others.

Indeed, more in-situ measured validation data are required to say for sure that the MLANN-albedo product may be able to retrieve albedo of sea ice in shallow-ocean areas better than the MCD43 product. However, the advantage of our product being 
https://doi.org/10.5194/tc-2021-397

Preprint. Discussion started: 18 January 2022

(c) Author(s) 2022. CC BY 4.0 License.

\section{(c) (i)}

able to provide retrieval for any clear-sky day should be emphasized, while MCD43A3 needs enough observations during a 16-day window.

\subsection{Comparison with the MERIS-albedo product}

Istomina et al. (2015); Istomina (2020) developed two albedo retrieval products, utilizing MERIS data from Envisat-1 and OLCI data from Sentinel-3, respectively. The MERIS sensor only operated between 2002 and 2012, and the OLCI-product is the successor to the MERIS-albedo product (Istomina et al., 2015); both products are based on the melt-pond detector (MPD) algorithm proposed by Zege et al. (2015).

In Istomina et al. (2015), the MERIS-albedo product was evaluated by comparing the estimated albedo values to aerial observations from the MELTEX campaign. The best agreement was found for land-fast ice, with an R-squared value of 0.84 and an RMSE of 0.068 for 169 matched pixels. Figure 13 compares the retrieval results obtained using the MERIS- and MLANN-albedo retrieval algorithms during a 5-day period in 2007 between DOY 166 and 170. Additionally, to the right, the relevant melt pond fractions are given.

Note that in the MPD algorithm, the spectral reflection coefficients for the melt-pond and thin ice boundaries, as well as the thick ice and snow-cover boundaries, are adjusted based on the surface condition. Therefore, there are greater uncertainties in the retrieval during the transitional seasons of spring-summer and summer-autumn, as well as when the surface is highly heterogeneous (low sea ice concentration, Istomina et al. (2015)). As can be seen in Fig. 13, the two algorithms produce more consistent results for high sea ice concentration areas (panels (a) and (c)), but the MERIS-derived albedos in places with a large MPF (greater than 50\%) appear to be higher than those produced by the MLANN model (panels (b) and (d)).

Another difference to note is the empty areas in Fig. 13. Chen et al. (2018) and Fan et al. (2021) demonstrated that the MLCM model we used for cloud filtering is more strict than the MODIS cloud filtering algorithm and is capable of identifying very thin cloud (and even fog, see Section 3) on bright surfaces such as snow and ice. The empty areas in (a) and (b) are MLCMidentified thin cloud pixels, whereas the empty areas in (c) through (f) represent open-water areas that were not processed by the MPD algorithm (Istomina et al., 2015).

\subsection{Comparison with the OLCI-albedo product}

Figure 14 depicts OLCI- and MLANN-albedo retrievals on June 24, 2017 and June 26, 2017. Additionally, broadband albedo

515 values obtained using pyranometers Stapf et al. (2019) are displayed on top of the RGB images to serve as a 'ground truth' reference.

In the MPD algorithm, the type of ice used to calculate the ice-BRDF is referred to as 'white ice' (Zege et al., 2015), which forms when melt water drains intermittently from sea ice and has a few centimetres thick white coating that scatters light similarly to a thin snow layer (Grenfell and Warren, 1999; Tschudi et al., 2008).

Due to the logic of the underlying MPD algorithm, the OLCI- and MERIS albedo products place a premium on the melt pond areas in the two polar regions; the MPD method also provides melt pond fractions in addition to surface albedo. Because of the algorithm's emphasis on summer melting ice, it has various limitations, including being only applicable for data gathered from 

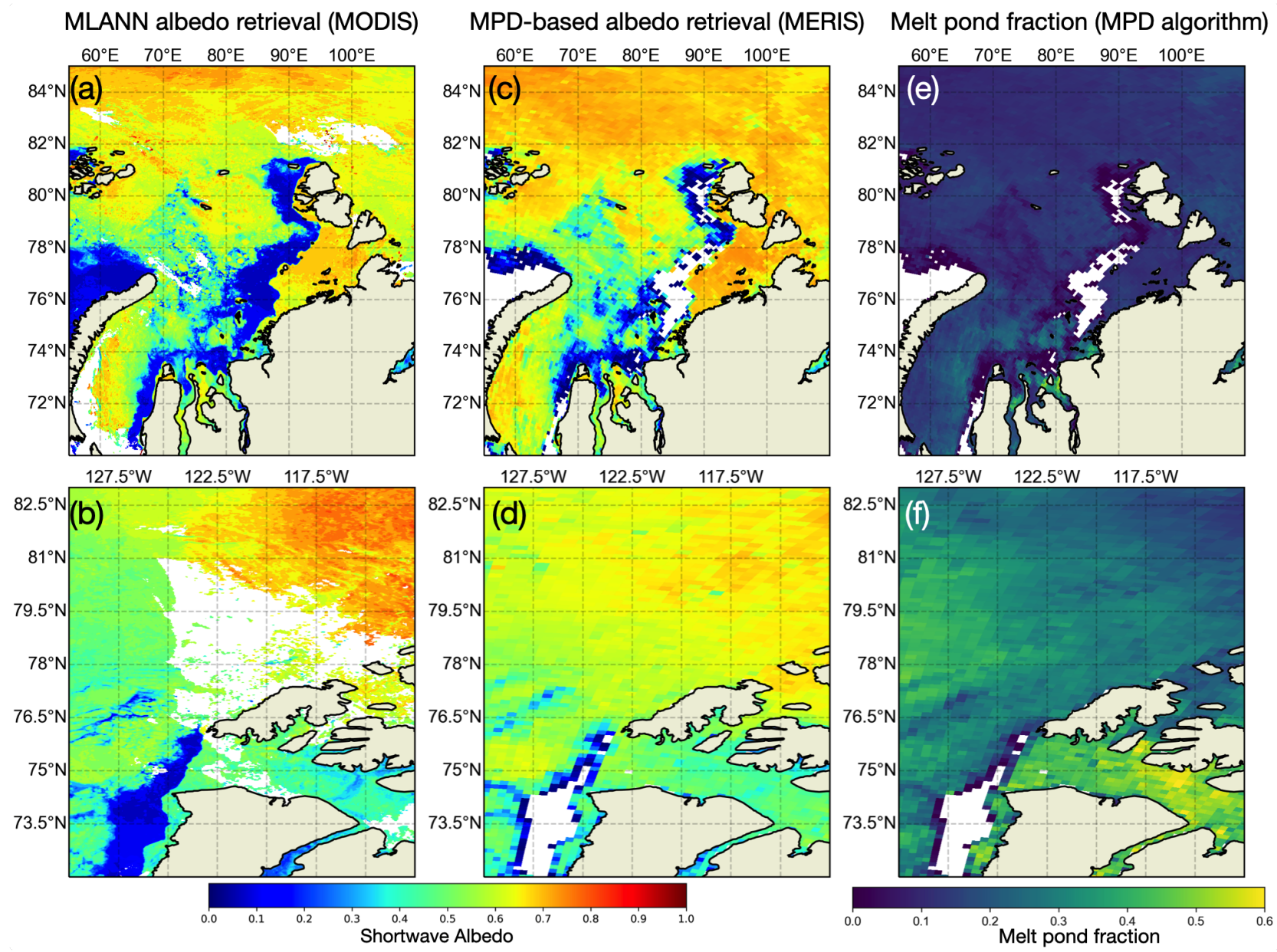

Figure 13. Maps of albedo and melt pond fraction averaged during a 5-day period in 2007 between DOY 166 and 170 . From left to right: MLANN-based and MPD-based albedo retrievals, as well as the MPD-derived melt pond fraction, respectively (Qu et al. (2015), this study, and Istomina et al. (2015)). The upper panels depict the Kara Sea, while the lower panels depict the Banks, Prince Patrick, and Melville Islands. At the bottom, colorbars representing the corresponding values are displayed. In panels (a) and (b), empty regions represent cloud pixels that were detected by the MLCM cloud mask (and hence removed), whereas empty regions in panels (c) through (f) represent either cloud pixels or open-water areas that were not processed by the MPD algorithm. 

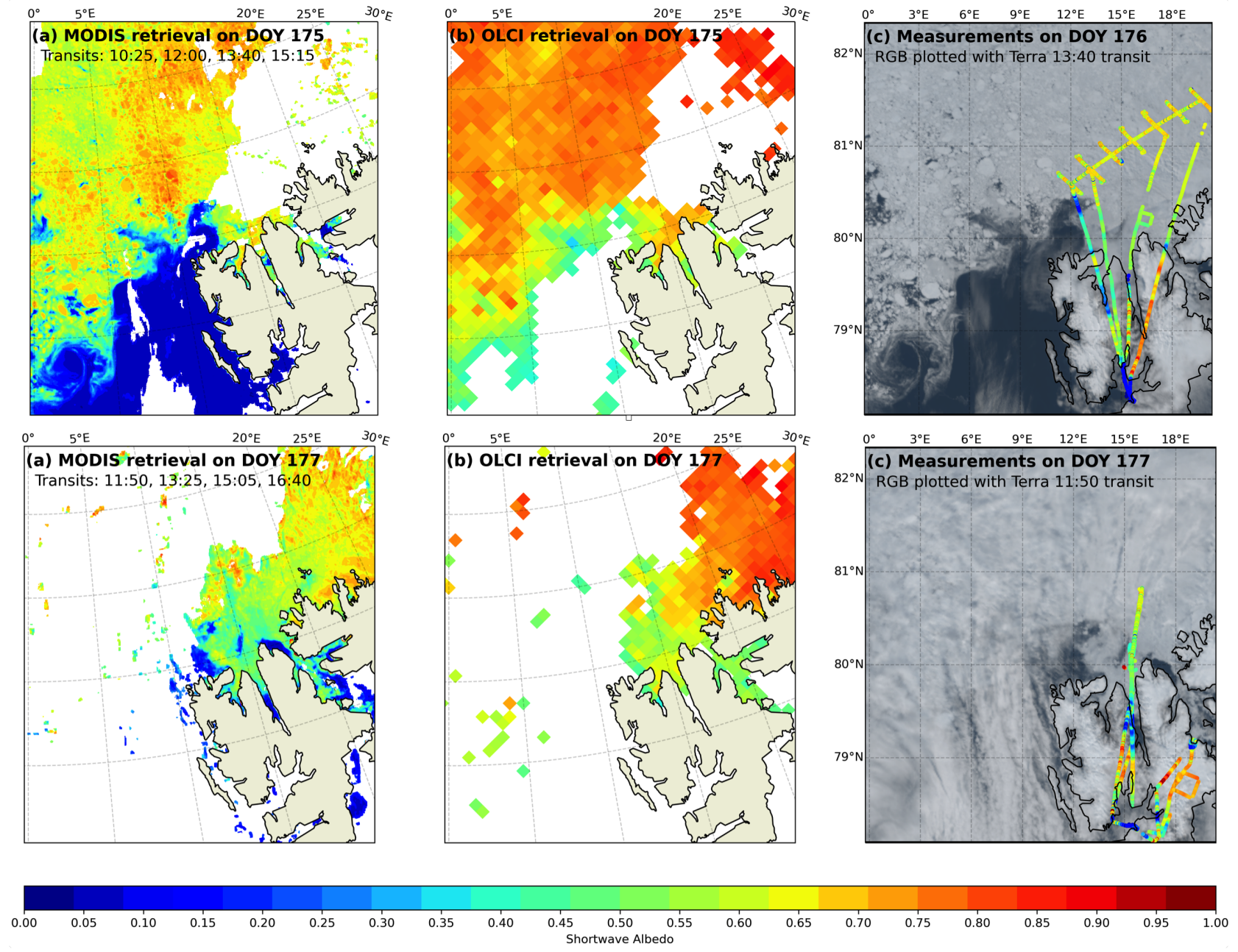

Figure 14. Maps of albedo derived using MLANN (MODIS data) and the MPD algorithm (OLCI data, Istomina (2020)). The top panels depict albedo values on June 24, 2017, while the bottom panels depict values on June 26, 2017. From left to right, panels depict retrievals using MLANN, MPD, and pyranometer measurements layered on an RGB image. On the associated images, the MODIS transits used to retrieve albedo and plot the RGB are labeled. Notably, no OLCI retrieval was available on June 25, 2017, and the campaign measurements for reference were taken on June 25 and 26. 
May to August, having a limited ability to retrieve albedo on snow-covered ice and ice with brine pockets inclusions, omitting retrieval for open-water areas, and having restrictions in areas with low sea ice concentration and very thin ponded ice. When OLCI albedo maps are compared to in-situ data (Fig. 14 (b)-(c)), it is clear that the derived albedo values for snow-covered ice are excessively high ( 0.75 to 0.82 , versus 0.65 to 0.7 ). On June 26,2017 (DOY 177), the RGB image shows a few open water spots around the northern coastline that are not captured by OLCI. This failure is partly attributable to the product's spatial resolution; data from its original resolutions (300 $\mathrm{m}$ at full resolution and $1.2 \mathrm{~km}$ at reduced resolution) were mapped to a $12.5-\mathrm{km}$ NSIDC grid. However, the main reason is that the MPD employs pixels solely from sea ice grid cells, and that open water pixels have been filtered out using a brightness criterion.

By comparison, the MLANN-albedo algorithm is capable of retaining the surface's albedo truethfully regardless of its condition and accurately reflecting the albedo values of these surfaces (i.e. more consistent with the measured albedo values). The current MLCM tool does not discriminate melt ponds from bare ice (both are labeled 'sea ice'). Because the MPD algorithm employs reflectance values from three visible channels ( $442 \mathrm{~nm}, 490 \mathrm{~nm}$, and $510 \mathrm{~nm}$ ), we may use a similar criterion to derive the melt pond fraction from MODIS or perhaps other sensors as well.

\subsection{Discussion}

Our RTM/SciML albedo retrieval tool is not perfect. There are still uncertainties associated with the ice and snow surfaces due to surface roughness and topographic shading, which present a challenge for any satellite remote sensing methods. For simplicity, the snow or ice does not exhibit layered topographic variation in the current training data. Also, the current RTM/SciML albedo retrieval tool does not account for whitecaps and sun glints on the open ocean surface that would occur at oblique viewing angles. Nevertheless, these constraints can be properly addressed by expanding the SD based on pertinent RTM simulations.

Additionally, because a flat layer of glacier ice is similar to sea ice without brine pockets and the two have a similar density (Warren, 2019), the RTM/SciML albedo algorithm presented here may be used to retrieve albedo of relatively flat glaciers.

545 To make RTM/SciML models more applicable to the glacier surface, the training table for RTM/SciML models should be updated to incorporate RTM-simulated radiance and albedo for a rough surface. The 'wind-roughened air-water interface' can be represented in AccuRT using a one- or two-dimensional Gaussian surface slope distribution (for details see Stamnes et al. (2018)). In comparison to the existing method for retrieving glacier albedo (Ren et al., 2021), which uses the measured BRDF of sea ice to approximate glacier-BRDF (Gatebe and King, 2016) and bi-conical band reflectance observed by a space-borne imaging radiometer to approximate the ice albedo in the shortwave-infrared band, the methodology we propose here may be more appropriate for characterizing the anisotropy reflectance of a rough glacier surface.

In summary, the RTM/SciML albedo retrieval tool established in this study is better capable of characterizing the albedo of complex cryosphere surfaces than currently available methods. 


\section{Conclusion}

In this paper, we have developed a new RTM/SciML sea ice albedo retrieval tool that can be applied to any optical sensor that measures appropriate radiance data. Evaluation of retrieved albedo values based on over 2000 data points obtained under cloud-free conditions revealed a small mean absolute error of 0.047 , compared to albedo values measured on low-level aircraft flights. Comparisons of the retrieval results from SGLI and MODIS sensors with measurements showed good agreement, indicating the reliability of the new RTM/SciML sea ice albedo retrieval tool.

The RTM/SciML-albedo algorithm was trained on a large synthetic dataset generated using a coupled RTM, and represents the optical properties of the cryosphere surface (bare ice, snow-covered ice, water, and melt pond). The combination of these two characteristics enables it to exploit the advantages of both the AccuRT and the RTM/SciML simulation tools:

- In comparison to the melt pond fraction-based albedo retrieval approach, the RTM/SciML-albedo algorithm has the benefit of being applicable to a wide variety of cryosphere surfaces, both heterogeneous and homogeneous, and of being sensor-agnostic.

- When compared to the LUT-based method for albedo retrieval (e.g. Qu et al. (2016); Peng et al. (2018)), this method is advantageous in terms of obtaining the underlying logic of the training data, availed by the RTM/SciML model.

When building the SD, we can reap the benefit of AccuRT being a radiative transfer model for the coupled system that accurately incorporates atmosphere-snow-sea-ice-water interactions to compute TOA radiances and corresponding surface albedo values. Information of both the surface BRDF and the IOPs of the atmosphere have already been taken into account. We are thus saved from the procedure to perform atmospheric corrections. In training and interpreting SciML models, we can be confident that the finalized RTM/SciML model could indeed learn the underlying physics (discussed in Zhou et al. (2021 (ready to submit)). Once a RTM/SciML model has been properly trained, it takes only a few seconds to make retrievals over an entire image from a satellite sensor.

This retrieval procedure does not rely on predefined spectral reflectance threshold values for individual types of surface; the surface classification and albedo retrieval are separate processes, which eliminates errors caused by incorrect surface condition assumptions. Even better, the albedo and reflectance differences between leads, ice floes, and melt ponds imply its potential for melt pond and lead identification, as demonstrated by Lee et al. (2016, 2020), who trained a MLANN algorithm for lead and melt pond detection using reflectance data.

580 Most importantly, the RTM/SciML framework presented and discussed here is generic in nature, allowing for comparisons not only between the MODIS sensors mounted on Terra and Aqua, but also to a large number of existing polar-orbiting sensors and well-planned future sensors, enabling sensor-to-sensor retrieval comparisons. In a recent review, Liang et al. (2019) emphasized the importance of developing retrieval algorithms that are broadly applicable to all satellite sensors: albedo retrievals based on multi-platform satellite sensors can significantly increase the amount of valid and accurate observational data, thereby increasing spatial and temporal coverage. Meanwhile, developing retrieval algorithms using the same methodology enables a 
https://doi.org/10.5194/tc-2021-397

Preprint. Discussion started: 18 January 2022

(c) Author(s) 2022. CC BY 4.0 License.

(c) (i)

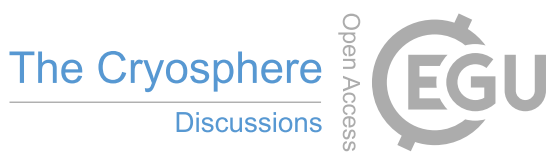

more extensive examination of the uncertainty associated with each sensor (e.g. identifying saturated channels and developing uncertainty assessment methods). The RTM/SciML framework presented in this paper is ideally suited for such a requirement.

Data availability. The H5 files of MODIS/SGLI retrieval (broadband albedo and surface classification) are intended to be published on PANGAEA. For the processed clear-sky validation data (matched pixels of MODIS-sensor radiance and campaign-measured albedo), please contact Yingzhen Zhou (yzhou64@stevens.edu).

\section{Appendix A}

\begin{tabular}{|c|c|c|c|c|}
\hline Date & Polar 5 & Polar 6 & MODIS & Cloud \% \\
\hline \multirow{3}{*}{31 May 2017} & \multirow{3}{*}{$15: 05-18: 57$} & \multirow{3}{*}{$14: 59-19: 03$} & $14: 30$ & \multirow{3}{*}{$31.35 \%$} \\
\hline & & & $16: 05$ & \\
\hline & & & $17: 45$ & \\
\hline \multirow{3}{*}{8 June 2017} & \multirow{3}{*}{$7: 36-12: 51$} & \multirow{3}{*}{$7: 30-12: 20$} & $12: 00$ & \multirow{3}{*}{$74.37 \%$} \\
\hline & & & $13: 40$ & \\
\hline & & & $15: 15$ & \\
\hline \multirow{4}{*}{18 June 2017} & \multirow{4}{*}{$12: 03-17: 55$} & \multirow{4}{*}{$12: 25-17: 50$} & 11:00 & \multirow{4}{*}{$82.69 \%$} \\
\hline & & & $12: 40$ & \\
\hline & & & $14: 15$ & \\
\hline & & & $15: 55$ & \\
\hline \multirow{4}{*}{25 June 2017} & \multirow{4}{*}{ 11:09-17:11 } & \multirow{4}{*}{$11: 03-16: 56$} & $11: 05$ & \multirow{4}{*}{$28.06 \%$} \\
\hline & & & $12: 45$ & \\
\hline & & & $14: 20$ & \\
\hline & & & $16: 00$ & \\
\hline \multirow{4}{*}{26 June 2017} & \multirow{4}{*}{$12: 34-15: 17$} & \multirow{4}{*}{$12: 32-14: 48$} & $11: 50$ & \multirow{4}{*}{$33.74 \%$} \\
\hline & & & $13: 25$ & \\
\hline & & & $15: 05$ & \\
\hline & & & $16: 40$ & \\
\hline \multirow{2}{*}{ April 082019} & \multirow{2}{*}{$9: 11 \sim 13: 50$} & \multirow{2}{*}{ I } & $11: 30$ & \multirow{2}{*}{$46.52 \%$} \\
\hline & & & $13: 10$ & \\
\hline \multirow{2}{*}{ April 112019} & \multirow{2}{*}{$9: 42 \sim 12: 46$} & \multirow{2}{*}{ I } & $12: 00$ & \multirow{2}{*}{$81.12 \%$} \\
\hline & & & $13: 40$ & \\
\hline
\end{tabular}

Table A1. Time stamps for airborne observations, satellite overflights in UTC, and cloud pixel percentages in the latitude-longitude ranges of aircraft during the ACLOUD and AFLUX campaigns. Note that days with just broken-cloud observations (cloud coverage greater than $90 \%$ ) are not included in the table. 
https://doi.org/10.5194/tc-2021-397

Preprint. Discussion started: 18 January 2022

(c) Author(s) 2022. CC BY 4.0 License.

(c) (i)

\begin{tabular}{|c|c|c|c|c|c|c|c|c|c|c|}
\hline equipment (range) & surface & $r$ & RMSE & MAE & $\operatorname{MAPE}(\%)$ & $f_{\text {above }}$ & $f_{\text {below }}$ & $f_{E E \leq 15}$ & Bias & $\mathrm{N}$ \\
\hline \multirow{4}{*}{ albedometer VIS } & water & 0.89 & 0.053 & 0.046 & 37 & 1.2 & 3 & 96 & -0.005 & 248 \\
\hline & snow & 0.64 & 0.069 & 0.051 & 7.3 & 3.7 & 0 & 96 & -0.004 & 3423 \\
\hline & ice & 0.57 & 0.147 & 0.125 & 34.7 & 37.4 & 8 & 55 & 0.014 & 265 \\
\hline & all & 0.92 & 0.076 & 0.056 & 11 & 5.8 & 1 & 93 & 0.001 & 3936 \\
\hline \multirow{4}{*}{ albedometer NIR } & water & 0.83 & 0.032 & 0.021 & 20.3 & 1.2 & 3 & 96 & -0.009 & 248 \\
\hline & snow & 0.62 & 0.143 & 0.133 & 30.2 & 62.1 & 0 & 38 & 0.011 & 3423 \\
\hline & ice & 0.58 & 0.122 & 0.105 & 45.4 & 50.2 & 2 & 48 & 0.003 & 265 \\
\hline & all & 0.87 & 0.137 & 0.124 & 30.6 & 57.5 & 0 & 42 & 0.001 & 3936 \\
\hline \multirow{4}{*}{ albedometer SW } & water & 0.88 & 0.04 & 0.034 & 31.1 & 2 & 2 & 96 & -0.008 & 248 \\
\hline & snow & 0.66 & 0.084 & 0.067 & 12.1 & 8.4 & 0 & 91 & -0.002 & 3423 \\
\hline & ice & 0.56 & 0.139 & 0.119 & 41.4 & 46 & 3 & 51 & 0.009 & 265 \\
\hline & all & 0.91 & 0.087 & 0.068 & 15.3 & 10.5 & 0 & 89 & -0.003 & 3936 \\
\hline \multirow{4}{*}{ pyranometer } & water & 0.86 & 0.036 & 0.026 & 24.1 & 0.2 & 2 & 97 & -0.008 & 1113 \\
\hline & snow & 0.53 & 0.096 & 0.065 & 12.5 & 8.4 & 1 & 90 & -0.009 & 6257 \\
\hline & ice & 0.5 & 0.182 & 0.152 & 41.8 & 28.3 & 31 & 41 & 0.026 & 594 \\
\hline & all & 0.9 & 0.099 & 0.066 & 16.3 & 8.7 & 4 & 88 & -0.011 & 7964 \\
\hline
\end{tabular}

Table A2. Summary of the evaluation results for a time-constraint with a loose value $\left(\delta_{t} \leq 5\right.$-h). The data were divided into four categories: three broadband albedos determined by the albedometer's spectral range, and a broadband shortwave albedo determined by the pyranometer's range. Three subcategories have been identified within each category: snow-covered sea-ice (abbreviated as 'snow' in the table), bare sea-ice ('ice'), and open water ('water'). Pearson-r coefficient ( $r$ ), root mean square error (RMSE), mean absolute error (MAE), mean absolute percentage error (MAPE), $f_{\text {above }}, f_{E E \leq 15}, f_{\text {below }}$, and bias are used to evaluate the retrieval in the subcategories (snow, ice, and water) and the total valid data ('all'). On the right side of the table, the total number of data in each subgroup is included (N).

Author contributions. YZ and WL developed the framework for albedo retrieval; YZ conducted radiative transfer simulations, compiled satellite retrievals and wrote the manuscript; NC developed the surface classification algorithm; and YF, NC, and KS contributed to the discussion of the results. All co-authors assisted with manuscript editing and provided substantial input to the interpretation of the results.

Competing interests. The authors declare that they have no conflict of interest. 

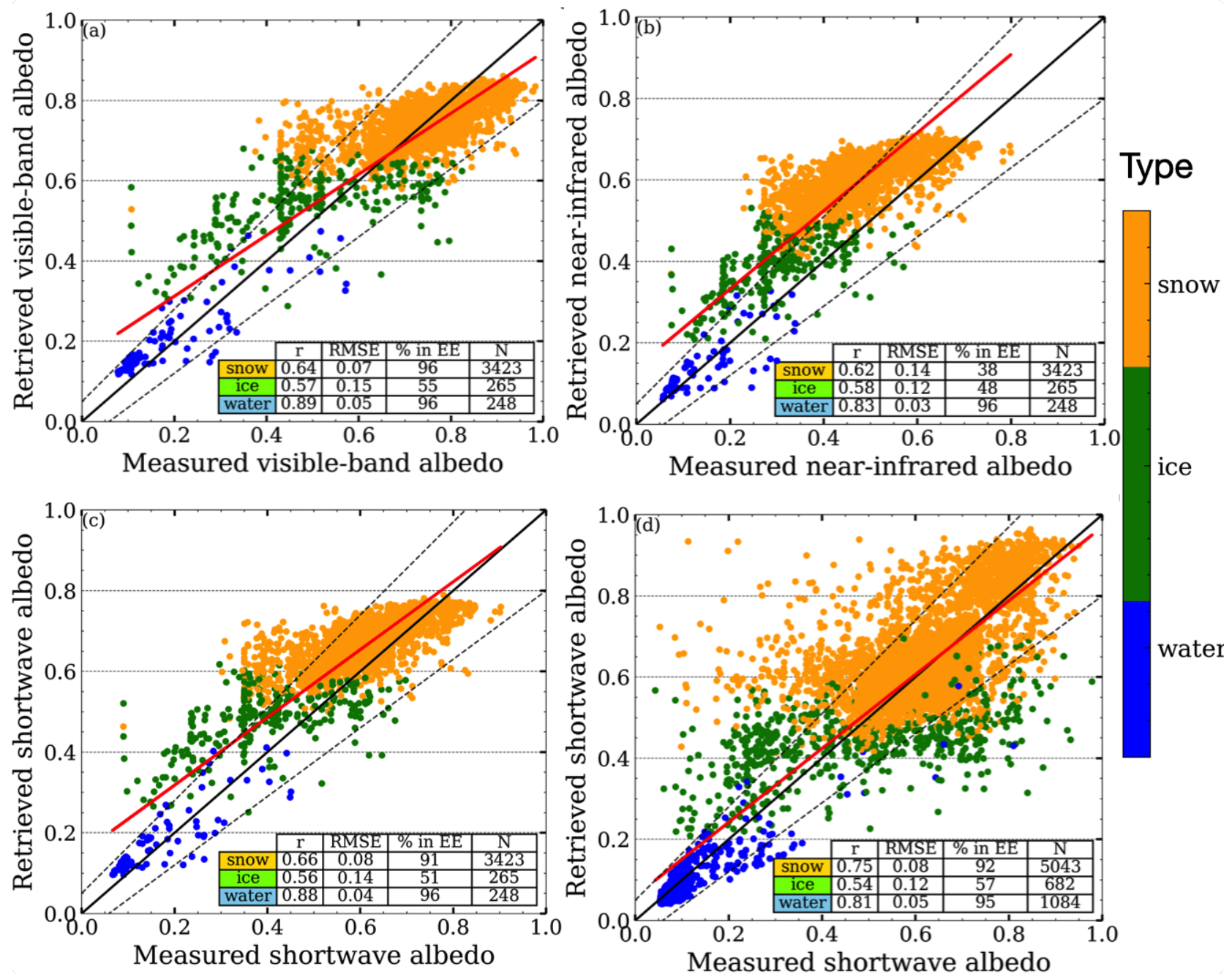

Figure A1. Same as Figure 3, but with the surface type represented by color. In addition, the lower right corner displays data for each surface type $\left(r\right.$, RMSE, $f_{E E \leq 15}$, and $\left.N\right)$. 
https://doi.org/10.5194/tc-2021-397

Preprint. Discussion started: 18 January 2022

(C) Author(s) 2022. CC BY 4.0 License.

(c) (1)

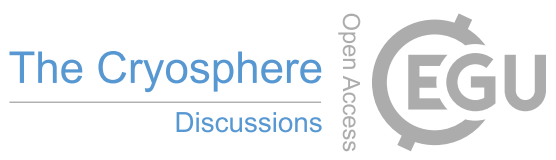

Acknowledgements. We thank Drs. Johannes Stapf and Evelyn Jäkel of Leipzig University for supplying the pyranometer and albedometer observations that are now available on PANGAEA. The melt pond fraction and MERIS/OLCI albedo were provided by the University of Bremen from their website at https://seaice.uni-bremen.de/databrowser/\#p=MERIS_OLCI_albedo (last access 27 December 2021). This work was partially supported by grants from the Japanese Aerospace eXploration Agency (JAXA) and by the United States National Aeronautics and Space Administration (NASA). 
https://doi.org/10.5194/tc-2021-397

Preprint. Discussion started: 18 January 2022

(c) Author(s) 2022. CC BY 4.0 License.

(c) (i)

\section{References}

MOSAiC Science Plan, 2016.

An, Y., Meng, X., Zhao, L., Li, Z., Wang, S., Shang, L., Chen, H., Lyu, S., Li, G., and Ma, Y.: Performance of GLASS and MODIS Satellite Albedo Products in Diagnosing Albedo Variations during Different Time Scales and Special Weather Conditions in the Tibetan Plateau, Remote Sensing, 12, 2456, https://doi.org/10.3390/rs12152456, 2020.

Anderson, G. P., Clough, S. A., Kneizys, F. X., Chetwynd, J. H., and Shettle, E. P.: AFGL Atmospheric Constituent Profiles (0.120km), 1986.

Barrientos Velasco, C., Deneke, H., and Macke, A.: Spatial and Temporal Variability of Broadband Solar Irradiance during POLARSTERN Cruise PS106/1 Ice Floe Camp (June 4th-16th 2017), https://doi.org/10.1594/PANGAEA.896710, 2018.

Bitz, C. M. and Roe, G. H.: A Mechanism for the High Rate of Sea Ice Thinning in the Arctic Ocean, Journal of Climate, 17, 3623-3632, https://doi.org/10.1175/1520-0442(2004)017<3623:AMFTHR>2.0.CO;2, 2004.

Braakmann-Folgmann, A. and Donlon, C.: Estimating Snow Depth on Arctic Sea Ice Using Satellite Microwave Radiometry and a Neural Network, The Cryosphere, 13, 2421-2438, https://doi.org/10.5194/tc-13-2421-2019, 2019.

Brandt, R. E., Warren, S. G., Worby, A. P., and Grenfell, T. C.: Surface Albedo of the Antarctic Sea Ice Zone, Journal of Climate, 18, 3606-3622, https://doi.org/10.1175/JCLI3489.1, 2005.

615 Cao, Y., Yang, X., and Zhu, X.: Retrieval Snow Depth by Artificial Neural Network Methodology from Integrated AMSR-E and in-Situ Data-A Case Study in Qinghai-Tibet Plateau, Chinese Geographical Science, https://doi.org/10.1007/s11769-008-0356-2, 2008.

Chen, N., Li, W., Gatebe, C., Tanikawa, T., Hori, M., Shimada, R., Aoki, T., and Stamnes, K.: New Neural Network Cloud Mask Algorithm Based on Radiative Transfer Simulations, Remote Sensing of Environment, 219, 62-71, https://doi.org/10.1016/j.rse.2018.09.029, 2018.

Chi, J., Kim, H.-c., Lee, S., and Crawford, M. M.: Deep Learning Based Retrieval Algorithm for Arctic Sea Ice Concentration from AMSR2

Passive Microwave and MODIS Optical Data, Remote Sensing of Environment, 231, 111 204, https://doi.org/10.1016/j.rse.2019.05.023, 2019.

Comiso, J. C. and Hall, D. K.: Climate Trends in the Arctic as Observed from Space, WIREs Climate Change, 5, 389-409, https://doi.org/10.1002/wcc.277, 2014.

Curry, J. A., Schramm, J. L., and Ebert, E. E.: Sea Ice-Albedo Climate Feedback Mechanism, Journal of Climate, 8, 240-247, https://doi.org/10.1175/1520-0442(1995)008<0240:SIACFM>2.0.CO;2, 1995.

De Keukelaere, L., Sterckx, S., Adriaensen, S., Knaeps, E., Reusen, I., Giardino, C., Bresciani, M., Hunter, P., Neil, C., Van der Zande, D., and Vaiciute, D.: Atmospheric Correction of Landsat-8/OLI and Sentinel-2/MSI Data Using iCOR Algorithm: Validation for Coastal and Inland Waters, European Journal of Remote Sensing, 51, 525-542, https://doi.org/10.1080/22797254.2018.1457937, 2018.

Dumont, M., Brissaud, O., Picard, G., Schmitt, B., Gallet, J.-C., and Arnaud, Y.: High-Accuracy Measurements of Snow Bidirectional Reflectance Distribution Function at Visible and NIR Wavelengths - Comparison with Modelling Results, Atmospheric Chemistry and Physics, 10, 2507-2520, https://doi.org/10.5194/acp-10-2507-2010, 2010.

Ehrlich, A., Wendisch, M., Lüpkes, C., Buschmann, M., Bozem, H., Chechin, D., Clemen, H.-C., Dupuy, R., Eppers, O., Hartmann, J., et al.: A Comprehensive in Situ and Remote Sensing Data Set from the Arctic CLoud Observations Using Airborne Measurements during Polar Day (ACLOUD) Campaign, Earth System Science Data, 11, 1853-1881, https://doi.org/10.5194/essd-11-1853-2019, 2019.

Fan, Y., Li, W., Chen, N., Ahn, J.-H., Park, Y.-J., Kratzer, S., Schroeder, T., Ishizaka, J., Chang, R., and Stamnes, K.: OC-SMART: A Machine Learning Based Data Analysis Platform for Satellite Ocean Color Sensors, Remote Sensing of Environment, 253, 112 236, https://doi.org/10.1016/j.rse.2020.112236, 2021. 
https://doi.org/10.5194/tc-2021-397

Preprint. Discussion started: 18 January 2022

(c) Author(s) 2022. CC BY 4.0 License.

(c) (i)

Gatebe, C. K. and King, M. D.: Airborne Spectral BRDF of Various Surface Types (Ocean, Vegetation, Snow, Desert, Wetlands, Cloud Decks, Smoke Layers) for Remote Sensing Applications, Remote Sensing of Environment, 179, 131-148, https://doi.org/10.1016/j.rse.2016.03.029, 2016.

Gatebe, C. K., King, M. D., Lyapustin, A. I., Arnold, G. T., and Redemann, J.: Airborne Spectral Measurements of Ocean Directional Reflectance, Journal of the Atmospheric Sciences, 62, 1072-1092, https://doi.org/10.1175/JAS3386.1, 2005.

Gildor, H., Tziperman, E., and Toggweiler, J. R.: Sea Ice Switch Mechanism and Glacial-Interglacial CO2 Variations, Global Biogeochemical Cycles, 16, 6-1-6-14, https://doi.org/10.1029/2001gb001446, 2002.

Grenfell, T. C.: Seasonal and Spatial Evolution of Albedo in a Snow-Ice-Land-Ocean Environment, Journal of Geophysical Research, 109, C01 001, https://doi.org/10.1029/2003JC001866, 2004.

Grenfell, T. C. and Maykut, G. A.: The Optical Properties of Ice and Snow in the Arctic Basin, Journal of Glaciology, 18, 445-463, 1977.

Grenfell, T. C. and Perovich, D. K.: Spectral Albedos of Sea Ice and Incident Solar Irradiance in the Southern Beaufort Sea, Journal of Geophysical Research: Oceans, 89, 3573-3580, https://doi.org/10.1029/JC089iC03p03573, 1984.

Grenfell, T. C. and Warren, S. G.: Representation of a Nonspherical Ice Particle by a Collection of Independent Spheres for Scattering and Absorption of Radiation, Journal of Geophysical Research: Atmospheres, 104, 31 697-31 709, https://doi.org/10.1029/1999JD900496, 1999.

Gröbner, J., Reda, I., Wacker, S., Nyeki, S., Behrens, K., and Gorman, J.: A New Absolute Reference for Atmospheric Longwave Irradiance Measurements with Traceability to SI Units, Journal of Geophysical Research: Atmospheres, 119, 7083-7090, https://doi.org/10.1002/2014JD021630, 2014.

Herbert, C., Munoz-Martin, J. F., Llaveria, D., Pablos, M., and Camps, A.: Sea Ice Thickness Estimation Based on Regression Neural Networks Using L-Band Microwave Radiometry Data from the FSSCat Mission, Remote Sensing, 13, 1366, https://doi.org/10.3390/rs13071366, 2021.

Hu, Y., Che, T., Dai, L., and Xiao, L.: Snow Depth Fusion Based on Machine Learning Methods for the Northern Hemisphere, Remote Sensing, https://doi.org/10.3390/rs13071250, 2021.

Istomina, L.: Retrieval of Sea Ice Surface Melt Using OLCI Data Onboard Sentinel-3, American Geophysical Union, Fall Meeting 2020, 2020, C017-07, 2020.

Istomina, L., Heygster, G., Huntemann, M., Schwarz, P., Birnbaum, G., Scharien, R., Polashenski, C., Perovich, D., Zege, E., Malinka, A., Prikhach, A., and Katsev, I.: Melt Pond Fraction and Spectral Sea Ice Albedo Retrieval from MERIS Data - Part 1: Validation against in Situ, Aerial, and Ship Cruise Data, The Cryosphere, 9, 1551-1566, https://doi.org/10.5194/tc-9-1551-2015, 2015.

Jäkel, E., Ehrlich, A., Schäfer, M., and Wendisch, M.: Aircraft Measurements of Up- and Downward Irradiances over Arctic Sea Ice during the ACLOUD Campaign, https://doi.org/10.1594/PANGAEA.891588, 2018.

Jäkel, E., Stapf, J., Wendisch, M., Nicolaus, M., Dorn, W., and Rinke, A.: Validation of the Sea Ice Surface Albedo Scheme of the Regional Climate Model HIRHAM-NAOSIM Using Aircraft Measurements during the ACLOUD/PASCAL Campaigns, The Cryosphere, 13, 1695-1708, https://doi.org/10.5194/tc-13-1695-2019, 2019.

Jäkel, E., Carlsen, T., Ehrlich, A., Wendisch, M., Schäfer, M., Rosenburg, S., Nakoudi, K., Zanatta, M., Birnbaum, G., Helm, V., et al.: Comparison of Optical-Equivalent Snow Grain Size Estimates under Arctic Low Sun Conditions during PAMARCMiP 2018, The Cryosphere Discussions, pp. 1-36, https://doi.org/10.5194/tc-2021-14, 2021a.

Jäkel, E., Schäfer, M., Ehrlich, A., Becker, S., and Klingebiel, M.: Aircraft Measurements of Spectral Solar Up- and Downward Irradiances in the Arctic during the MOSAiC-ACA Campaign 2020, https://doi.org/10.1594/PANGAEA.933850, 2021 b. 
https://doi.org/10.5194/tc-2021-397

Preprint. Discussion started: 18 January 2022

(c) Author(s) 2022. CC BY 4.0 License.

(c) (i)

Jin, H., Song, Q., and Hu, X.: Auto-Keras: An Efficient Neural Architecture Search System, arXiv:1806.10282 [cs, stat], 2019.

Karvonen, J.: Baltic Sea Ice Concentration Estimation Using SENTINEL-1 SAR and AMSR2 Microwave Radiometer Data, IEEE Transactions on Geoscience and Remote Sensing, 55, 2871-2883, https://doi.org/10.1109/TGRS.2017.2655567, 2017.

Key, J., Wang, X., Liu, Y., Dworak, R., and Letterly, A.: The AVHRR Polar Pathfinder Climate Data Records, Remote Sensing, 8, 167, https://doi.org/10.3390/rs8030167, 2016.

Knap, W. H., Reijmer, C. H., and Oerlemans, J.: Narrowband to Broadband Conversion of Landsat TM Glacier Albedos, International Journal of Remote Sensing, 20, 2091-2110, https://doi.org/10.1080/014311699212362, 1999.

Knudsen, E. M., Heinold, B., Dahlke, S., Bozem, H., Crewell, S., Gorodetskaya, I. V., Heygster, G., Kunkel, D., Maturilli, M., Mech, M., Viceto, C., Rinke, A., Schmithüsen, H., Ehrlich, A., Macke, A., Lüpkes, C., and Wendisch, M.: Meteorological Conditions during the ACLOUD/PASCAL Field Campaign near Svalbard in Early Summer 2017, Atmospheric Chemistry and Physics, 18, 17 995-18 022, https://doi.org/10.5194/acp-18-17995-2018, 2018.

Kokhanovsky, A., Box, J. E., Vandecrux, B., Mankoff, K. D., Lamare, M., Smirnov, A., and Kern, M.: The Determination of Snow Albedo from Satellite Measurements Using Fast Atmospheric Correction Technique, Remote Sensing, 12, 234, https://doi.org/10.3390/rs12020234, 2020.

Kwok, R.: Arctic Sea Ice Thickness, Volume, and Multiyear Ice Coverage: Losses and Coupled Variability (1958-2018), Environmental Research Letters, 13, 105 005, https://doi.org/10.1088/1748-9326/aae3ec, 2018.

Kwok, R. and Rothrock, D. A.: Decline in Arctic Sea Ice Thickness from Submarine and ICESat Records: 1958-2008: ARCTIC SEA ICE THICKNESS, Geophysical Research Letters, 36, n/a-n/a, https://doi.org/10.1029/2009GL039035, 2009.

LeCun, Y., Bengio, Y., and Hinton, G.: Deep Learning, Nature, 521, 436-444, https://doi.org/10.1038/nature14539, 2015.

Lee, G., Kim, D., Kwon, H.-H., and Choi, E.: Estimation of Maximum Daily Fresh Snow Accumulation Using an Artificial Neural Network Model, Advances in Meteorology, https://doi.org/10.1155/2019/2709351, 2019.

Lee, S., Im, J., Kim, J., Kim, M., Shin, M., Kim, H.-c., and Quackenbush, L.: Arctic Sea Ice Thickness Estimation from CryoSat-2 Satellite Data Using Machine Learning-Based Lead Detection, Remote Sensing, 8, 698, https://doi.org/10.3390/rs8090698, 2016.

Lee, S., Stroeve, J., Tsamados, M., and Khan, A. L.: Machine Learning Approaches to Retrieve Pan-Arctic Melt Ponds from Visible Satellite Imagery, Remote Sensing of Environment, 247, 111919, https://doi.org/10.1016/j.rse.2020.111919, 2020.

Li, W., Stamnes, K., Eide, H., and Spurr, R.: Bidirectional Reflectance Distribution Function of Snow: Corrections for the Lambertian Assumption in Remote Sensing Applications, Optical Engineering, 46, 066 201, https://doi.org/10.1117/1.2746334, 2007.

Liang, S.: Narrowband to Broadband Conversions of Land Surface Albedo I Algorithms, Remote Sensing of Environment, p. $26,2000$.

Liang, S.: Mapping Daily Snow/Ice Shortwave Broadband Albedo from Moderate Resolution Imaging Spectroradiometer (MODIS): The Improved Direct Retrieval Algorithm and Validation with Greenland in Situ Measurement, Journal of Geophysical Research, 110 , D10 109, https://doi.org/10.1029/2004JD005493, 2005.

Liang, S., Wang, D., He, T., and Yu, Y.: Remote Sensing of Earth's Energy Budget: Synthesis and Review, International Journal of Digital Earth, 12, 737-780, https://doi.org/10.1080/17538947.2019.1597189, 2019.

Libois, Q., Picard, G., France, J. L., Arnaud, L., Dumont, M., Carmagnola, C. M., and King, M. D.: Influence of Grain Shape on Light Penetration in Snow, The Cryosphere, 7, 1803-1818, https://doi.org/10.5194/tc-7-1803-2013, 2013.

Lindsay, R.: Arctic Sea-Ice Albedo Derived from RGPS-based Ice-Thickness Estimates, Annals of Glaciology, 33, 225-229, https://doi.org/10.3189/172756401781818103, 2001. 
https://doi.org/10.5194/tc-2021-397

Preprint. Discussion started: 18 January 2022

(c) Author(s) 2022. CC BY 4.0 License.

(c) (i)

Liu, N. F., Liu, Q., Wang, L. Z., Liang, S. L., Wen, J. G., Qu, Y., and Liu, S. H.: A Statistics-Based Temporal Filter Algorithm to Map Spatiotemporally Continuous Shortwave Albedo from MODIS Data, Hydrology and Earth System Sciences, 17, 2121-2129, https://doi.org/10.5194/hess-17-2121-2013, 2013.

Lucht, W. and Lewis, P.: Theoretical Noise Sensitivity of BRDF and Albedo Retrieval from the EOS-MODIS and MISR Sensors with Respect to Angular Sampling, International Journal of Remote Sensing, 21, 81-98, https://doi.org/10.1080/014311600211000, 2000.

Lucht, W., Schaaf, C., and Strahler, A.: An Algorithm for the Retrieval of Albedo from Space Using Semiempirical BRDF Models, IEEE Transactions on Geoscience and Remote Sensing, 38, 977-998, https://doi.org/10.1109/36.841980, 2000.

Lüpkes, C.: Aircraft Campaign Arctic Boundary Layer Fluxes (AFLUX) 2019, in: EPIC3Workshop on Airborne Activities in the Arctic: Science and Prospects, Leipzig, 2017-10-05-2017-10-05Leipzig, Leipzig, 2017.

Martonchik, J. V., Bruegge, C. J., and Strahler, A. H.: A Review of Reflectance Nomenclature Used in Remote Sensing, Remote Sensing Reviews, 19, 9-20, https://doi.org/10.1080/02757250009532407, 2000.

Mehta, M., Singh, R., Singh, A., Singh, N., and Anshumali: Recent Global Aerosol Optical Depth Variations and Trends - A Comparative Study Using MODIS and MISR Level 3 Datasets, Remote Sensing of Environment, 181, 137-150, https://doi.org/10.1016/j.rse.2016.04.004, 2016.

Peng, J., Yu, Y., Yu, P., and Liang, S.: The VIIRS Sea-Ice Albedo Product Generation and Preliminary Validation, Remote Sensing, 10, 1826, https://doi.org/10.3390/rs10111826, 2018.

Perovich, D. K.: Seasonal Evolution of the Albedo of Multiyear Arctic Sea Ice, Journal of Geophysical Research, 107, 8044, https://doi.org/10.1029/2000JC000438, 2002.

Petrich, C. and Eicken, H.: Growth, Structure and Properties of Sea Ice, in: Sea Ice, edited by Thomas, D. N. and Dieckmann, G. S., pp. 23-77, Wiley-Blackwell, Oxford, UK, https://doi.org/10.1002/9781444317145.ch2, 2009.

Pithan, F. and Mauritsen, T.: Arctic Amplification Dominated by Temperature Feedbacks in Contemporary Climate Models, Nature Geoscience, 7, https://doi.org/10.1038/NGEO2071, 2014.

Pohl, C., Istomina, L., Tietsche, S., Jäkel, E., Stapf, J., Spreen, G., and Heygster, G.: Broadband Albedo of Arctic Sea Ice from MERIS Optical Data, The Cryosphere, 14, 165-182, https://doi.org/10.5194/tc-14-165-2020, 2020.

Pope, E. L., Willis, I. C., Pope, A., Miles, E. S., Arnold, N. S., and Rees, W. G.: Contrasting Snow and Ice Albedos Derived from MODIS, Landsat ETM+ and Airborne Data from Langjökull, Iceland, Remote Sensing of Environment, 175, 183-195, https://doi.org/10.1016/j.rse.2015.12.051, 2016.

Qu, Y., Liang, S., Liu, Q., He, T., Liu, S., and Li, X.: Mapping Surface Broadband Albedo from Satellite Observations: A Review of Literatures on Algorithms and Products, Remote Sensing, 7, 990-1020, https://doi.org/10.3390/rs70100990, 2015.

Qu, Y., Liang, S., Liu, Q., Li, X., Feng, Y., and Liu, S.: Estimating Arctic Sea-Ice Shortwave Albedo from MODIS Data, Remote Sensing of Environment, 186, 32-46, https://doi.org/10.1016/j.rse.2016.08.015, 2016.

Ren, S., Miles, E. S., Jia, L., Menenti, M., Kneib, M., Buri, P., McCarthy, M. J., Shaw, T. E., Yang, W., and Pellicciotti, F.: Anisotropy Parameterization Development and Evaluation for Glacier Surface Albedo Retrieval from Satellite Observations, Remote Sensing, 13, 1714, https://doi.org/10.3390/rs13091714, 2021.

Riihelä, A., Manninen, T., Laine, V., Andersson, K., and Kaspar, F.: CLARA-SAL: A Global 28 Yr Timeseries of Earth's Black-Sky Surface Albedo, Atmospheric Chemistry and Physics, 13, 3743-3762, https://doi.org/10.5194/acp-13-3743-2013, 2013.

Robock, A.: Ice and Snow Feedbacks and the Latitudinal and Seasonal Distribution of Climate Sensitivity, Journal of the Atmospheric Sciences, 40, 986-997, https://doi.org/10.1175/1520-0469(1983)040<0986:IASFAT>2.0.CO;2, 1983. 
https://doi.org/10.5194/tc-2021-397

Preprint. Discussion started: 18 January 2022

(c) Author(s) 2022. CC BY 4.0 License.

(c) (i)

Rösel, A. and Kaleschke, L.: Exceptional Melt Pond Occurrence in the Years 2007 and 2011 on the Arctic Sea Ice Revealed from MODIS Satellite Data: MELT PONDS ON ARCTIC SEA ICE, Journal of Geophysical Research: Oceans, 117, n/a-n/a, https://doi.org/10.1029/2011JC007869, 2012.

Schaaf, C. and Wang, Z.: MCD43A2 MODIS/Terra+Aqua BRDF/Albedo Quality Daily L3 Global - 500m V006, $2015 \mathrm{a}$.

Schaaf, C. and Wang, Z.: MCD43D59 MODIS/Terra+Aqua BRDF/Albedo White Sky Albedo VIS Band Daily L3 Global 30ArcSec CMG, 2015b.

Schaaf, C. B., Gao, F., Strahler, A. H., Lucht, W., Li, X., Tsang, T., Strugnell, N. C., Zhang, X., Jin, Y., Muller, J.-P., Lewis, P., Barnsley, M., Hobson, P., Disney, M., Roberts, G., Dunderdale, M., Doll, C., d'Entremont, R. P., Hu, B., Liang, S., Privette, J. L., and Roy, D.: First Operational BRDF, Albedo Nadir Reflectance Products from MODIS, Remote Sensing of Environment, 83, 135-148, https://doi.org/10.1016/S0034-4257(02)00091-3, 2002.

Schaepman-Strub, G., Schaepman, M., Painter, T., Dangel, S., and Martonchik, J.: Reflectance Quantities in Optical Remote Sensing_Definitions and Case Studies, Remote Sensing of Environment, 103, 27-42, https://doi.org/10.1016/j.rse.2006.03.002, 2006.

Scott, D. W.: Multivariate Density Estimation: Theory, Practice, and Visualization, John Wiley \& Sons, 2015.

Serreze, M. C., Holland, M. M., and Stroeve, J.: Perspectives on the Arctic's Shrinking Sea-Ice Cover, science, 315, 1533-1536, https://doi.org/10.1126/science.1139426, 2007.

Stamnes, K., Hamre, B., Stamnes, J., Ryzhikov, G., Biryulina, M., Mahoney, R., Hauss, B., and Sei, A.: Modeling of Radiation Transport in Coupled Atmosphere-Snow-Ice-Ocean Systems, Journal of Quantitative Spectroscopy and Radiative Transfer, 112, 714-726, https://doi.org/10.1016/j.jqsrt.2010.06.006, 2011.

Stamnes, K., Hamre, B., Stamnes, S., Chen, N., Fan, Y., Li, W., Lin, Z., and Stamnes, J.: Progress in Forward-Inverse Modeling Based on Radiative Transfer Tools for Coupled Atmosphere-Snow/Ice-Ocean Systems: A Review and Description of the Accurt Model, Applied Sciences, 8, 2682, https://doi.org/10.3390/app8122682, 2018.

Stapf, J., Ehrlich, A., Jäkel, E., and Wendisch, M.: Aircraft Measurements of Broadband Irradiance during the ACLOUD Campaign in 2017, https://doi.org/10.1594/PANGAEA.900442, 2019.

Stapf, J., Ehrlich, A., and Wendisch, M.: Aircraft Measurements of Broadband Irradiance during the AFLUX Campaign in 2019, 2021a.

Stapf, J., Ehrlich, A., and Wendisch, M.: Influence of Thermodynamic State Changes on Surface Cloud Radiative Forcing in the Arctic: A Comparison of Two Approaches Using Data From AFLUX and SHEBA, Journal of Geophysical Research: Atmospheres, 126, https://doi.org/10.1029/2020JD033589, 2021b.

Stroeve, J., Box, J. E., Gao, F., Liang, S., Nolin, A., and Schaaf, C.: Accuracy Assessment of the MODIS 16-Day Albedo Product for Snow: Comparisons with Greenland in Situ Measurements, Remote Sensing of Environment, 94, 46-60, https://doi.org/10.1016/j.rse.2004.09.001, 2005.

Stroeve, J., Holland, M. M., Meier, W., Scambos, T., and Serreze, M.: Arctic Sea Ice Decline: Faster than Forecast, Geophysical research letters, 34, https://doi.org/10.1029/2007GL029703, 2007.

Sturm, M. and Holmgren, J.: An Automatic Snow Depth Probe for Field Validation Campaigns, Water Resources Research, 54, 9695-9701, https://doi.org/10.1029/2018WR023559, 2018.

Tedesco, M. and Jeyaratnam, J.: A New Operational Snow Retrieval Algorithm Applied to Historical AMSR-E Brightness Temperatures, Remote Sensing, 8, 1037, https://doi.org/10.3390/rs8121037, 2016.

Tedesco, M., Pulliainen, J., Takala, M., Hallikainen, M., and Pampaloni, P.: Artificial Neural Network-Based Techniques for the Retrieval of SWE and Snow Depth from SSM/I Data, Remote Sensing of Environment, 90, 76-85, https://doi.org/10.1016/j.rse.2003.12.002, 2004. 
https://doi.org/10.5194/tc-2021-397

Preprint. Discussion started: 18 January 2022

(c) Author(s) 2022. CC BY 4.0 License.

(c) (i)

Toyota, T., Ukita, J., Ohshima, K. I., Wakatsuchi, M., and Muramoto, K.: A Measurement of Sea Ice Albedo over the Southwestern Okhotsk

Sea, Journal of the Meteorological Society of Japan. Ser. II, 77, 117-133, https://doi.org/10.2151/jmsj1965.77.1_117, 1999.

Tschudi, M., Stroeve, J., and Stewart, J.: Relating the Age of Arctic Sea Ice to Its Thickness, as Measured during NASA's ICESat and IceBridge Campaigns, Remote Sensing, 8, 457, https://doi.org/10.3390/rs8060457, 2016.

Tschudi, M. A., Maslanik, J. A., and Perovich, D. K.: Derivation of Melt Pond Coverage on Arctic Sea Ice Using MODIS Observations, Remote Sensing of Environment, 112, 2605-2614, https://doi.org/10.1016/j.rse.2007.12.009, 2008.

Turlach, B. A.: Bandwidth Selection in Kernel Density Estimation: A Review, in: CORE and Institut de Statistique, Citeseer, 1993.

Tynes, H. H., Kattawar, G. W., Zege, E. P., Katsev, I. L., Katsev, I. L., Prikhach, A. S., Chaikovskaya, L. I., and Chaikovskaya, L.: Monte Carlo and Multicomponent Approximation Methods for Vector Radiative Transfer by Use of Effective Mueller Matrix Calculations., Applied Optics, https://doi.org/10.1364/ao.40.000400, 2001.

Vermote, E., Tanre, D., Deuze, J., Herman, M., and Morcette, J.-J.: Second Simulation of the Satellite Signal in the Solar Spectrum, 6S: An

Overview, IEEE Transactions on Geoscience and Remote Sensing, 35, 675-686, https://doi.org/10.1109/36.581987, 1997.

Vihma, T., Pirazzini, R., Fer, I., Renfrew, I. A., Sedlar, J., Tjernström, M., Lüpkes, C., Nygård, T., Notz, D., Weiss, J., Marsan, D., Cheng, B., Birnbaum, G., Gerland, S., Chechin, D., and Gascard, J. C.: Advances in Understanding and Parameterization of Small-Scale Physical Processes in the Marine Arctic Climate System: A Review, Atmospheric Chemistry and Physics, 14, 9403-9450, https://doi.org/10.5194/acp14-9403-2014, 2014.

Wang, D., Liang, S., He, T., and Yu, Y.: Direct Estimation of Land Surface Albedo from VIIRS Data: Algorithm Improvement and Preliminary Validation: ESTIMATE LAND SURFACE ALBEDO FROM VIIRS, Journal of Geophysical Research: Atmospheres, 118, 12,577-12,586, https://doi.org/10.1002/2013JD020417, 2013.

Wang, J., Yuan, Q., Shen, H., Liu, T., Li, T., Yue, L., Shi, X., and Zhang, L.: Estimating Snow Depth by Combining Satellite Data and GroundBased Observations over Alaska: A Deep Learning Approach, Journal of Hydrology, https://doi.org/10.1016/j.jhydrol.2020.124828, 2020.

Wang, M. and Overland, J. E.: A Sea Ice Free Summer Arctic within 30 Years: An Update from CMIP5 Models, Geophysical Research Letters, 39, https://doi.org/10.1029/2012GL052868, 2012.

Wang, Z., Schaaf, C. B., Chopping, M. J., Strahler, A. H., Wang, J., Román, M. O., Rocha, A. V., Woodcock, C. E., and Shuai, Y.: Evaluation of Moderate-resolution Imaging Spectroradiometer (MODIS) Snow Albedo Product (MCD43A) over Tundra, Remote Sensing of Environment, 117, 264-280, https://doi.org/10.1016/j.rse.2011.10.002, 2012.

Warren, S. G.: Optical Properties of Ice and Snow, Philosophical Transactions of the Royal Society A: Mathematical, Physical and Engineering Sciences, 377, 20180 161, https://doi.org/10.1098/rsta.2018.0161, 2019.

Wendisch, M. and Brenguier, J.-L.: Airborne Measurements for Environmental Research: Methods and Instruments, John Wiley \& Sons, 2013.

Wendisch, M., Macke, A., Ehrlich, A., Lüpkes, C., Mech, M., Chechin, D., Dethloff, K., Velasco, C. B., Bozem, H., Brückner, M., et al.: The Arctic Cloud Puzzle: Using ACLOUD/PASCAL Multiplatform Observations to Unravel the Role of Clouds and Aerosol Particles in Arctic Amplification, Bulletin of the American Meteorological Society, 100, 841-871, https://doi.org/10.1175/BAMS-D-18-0072.1, 2019.

Winker, D. M., Tackett, J. L., Getzewich, B. J., Liu, Z., Vaughan, M. A., and Rogers, R. R.: The Global 3-D Distribution of Tropospheric Aerosols as Characterized by CALIOP, Atmospheric Chemistry and Physics, 13, 3345-3361, https://doi.org/10.5194/acp-13-3345-2013, 2013.

825 Xiong, X., Stamnes, K., and Lubin, D.: Surface Albedo over the Arctic Ocean Derived from AVHRR and Its Validation with SHEBA Data, JOURNAL OF APPLIED METEOROLOGY, 41, 14, https://doi.org/10.1175/1520-0450(2002)041<0413:SAOTAO>2.0.CO;2, 2002. 
https://doi.org/10.5194/tc-2021-397

Preprint. Discussion started: 18 January 2022

(C) Author(s) 2022. CC BY 4.0 License.

(c) (1)

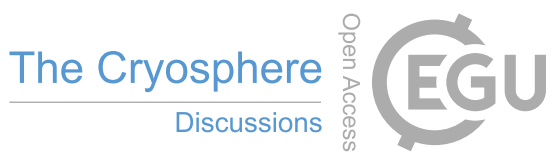

Zege, E., Malinka, A., Katsev, I., Prikhach, A., Heygster, G., Istomina, L., Birnbaum, G., and Schwarz, P.: Algorithm to Retrieve the Melt Pond Fraction and the Spectral Albedo of Arctic Summer Ice from Satellite Optical Data, Remote Sensing of Environment, 163, 153-164, https://doi.org/10.1016/j.rse.2015.03.012, 2015.

Zhou, Y., Li, W., Chen, N., Fan, Y., and Stamnes, K.: A Sensor-Agnostic Albedo Retrieval Method for All Sea Ice Surfaces - Model Interpretability and Applications in RCM/GCM as Well as CRF, The Cryosphere, 2021 (ready to submit).

Zhou, Y., Li, W., Chen, N., Fan, Y., Tomonori, T., Toyota, T., and Stamnes, K.: Spatiotemporal Variations of Sea Ice Albedo and Its Relation with Spring Bloom Occurrences: A Study of the Dynamics of Melt Ponds and Sea Ice Albedo in the Sea of Okhotsk, Journal of Oceanography, 2021 (submitted).

835 Zhu, L., Zhang, Y., Wang, J., Tian, W., Liu, Q., Ma, G., Kan, X., and Chu, Y.: Downscaling Snow Depth Mapping by Fusion of Microwave and Optical Remote Sensing Data Based on Deep Learning, Remote Sensing, https://doi.org/10.3390/rs 13040584, 2021. 